\title{
On contractive cyclic fuzzy maps in metric spaces and some related results on fuzzy best proximity points and fuzzy fixed points
}

\author{
Manuel De la Sen ${ }^{*}$, Antonio F Roldán ${ }^{2}$ and Ravi P Agarwal ${ }^{3,4}$
}

\author{
"Correspondence: \\ manuel.delasen@ehu.eus \\ ${ }^{1}$ Institute of Research and \\ Development of Processes, \\ University of the Basque Country, \\ Campus of Leioa (Bizkaia), Barrio \\ Sarriena, P.O. Box 644, Bilbao, 48940, \\ Spain \\ Full list of author information is \\ available at the end of the article
}

\begin{abstract}
This paper investigates some properties of cyclic fuzzy maps in metric spaces. The convergence of distances as well as that of sequences being generated as iterates defined by a class of contractive cyclic fuzzy mapping to fuzzy best proximity points of (non-necessarily intersecting adjacent subsets) of the cyclic disposal is studied. An extension is given for the case when the images of the points of a class of contractive cyclic fuzzy mappings restricted to a particular subset of the cyclic disposal are allowed to lie either in the same subset or in its next adjacent one.
\end{abstract}

Keywords: fixed and best proximity points; fuzzy cyclic contractive maps; cyclic fuzzy contraction and fuzzy sets

\section{Introduction}

Fixed point theory has received much attention in the last decades with a rapidly increasing number of related theorems on nonexpansive and on contractive mappings, variational inequalities, optimization etc. Variants and extensions have also been considered in the frameworks of probabilistic metric spaces and multivalued mappings. The wide variety of problems of cyclic and proximal contractions has also received much attention in the last years.

Fixed point theory has also proved to be an important tool for the study of relevant problems in science and engineering concerning local and global stability, asymptotic stability, stabilization, convergence of trajectories and sequences to equilibrium points [1-3], dynamics switching in dynamic systems and in differential/difference equations, etc. In particular, the equilibrium problems associated with switching processes in dynamic systems [1-4] are sometimes related to cyclic mappings where the cyclic disposal contains either trajectory solutions or sequences which commute to adjacent subsets being appropriately defined. Cyclic mappings, related contractive properties, and best proximity points have been widely studied in metric spaces in both the deterministic [5-10] and the probabilistic frameworks, see, for instance, [11-14], as well the related proximal-type problems, see, for instance, $[15,16]$ and references therein.

The concept of fuzzy contractions was proposed in [17] and has been revisited later on in [18-21] including the study the common fixed points and compatibility problems in fuzzy metric spaces, [22-28]. In particular the paper by Azam and Beg [22] is very

(c) 2015 De la Sen et al. This article is distributed under the terms of the Creative Commons Attribution 4.0 International License (http://creativecommons.org/licenses/by/4.0/), which permits unrestricted use, distribution, and reproduction in any medium, provided you give appropriate credit to the original author(s) and the source, provide a link to the Creative Commons license, and indicate if changes were made. 
illustrative and well worked out on a set of proved properties associated with a very general fuzzy contractive condition. On the other hand, a fuzzy theory related to the more general intuitionistic fuzzy metric spaces is also being developed. See, for instance, $[29,30]$ and references therein. See also the recent references [31, 32].

The main objective of this paper is the study of contractive fuzzy cyclic multivalued mappings and the convergence properties of sequences constructed via such maps to fuzzy best proximity points and fuzzy fixed points. It is assumed that the subsets defining the cyclic disposal do not necessarily intersect. Some extended results are given for the more general case when the cyclic map can have an image within its domain instead of on its adjacent subset of the cyclic disposal.

\subsection{Notation}

$\bar{n}=\{1,2, \ldots, n\}$;

$\mathbf{Z}_{0+}, \mathbf{Z}_{+}$, and $\mathbf{Z}$ are the sets of nonnegative integers, positive integers, and integers, respectively;

$\mathbf{R}_{0+}, \mathbf{R}_{+}$, and $\mathbf{R}$ are the sets of nonnegative real numbers, positive real numbers, and real numbers, respectively.

\section{Some preliminaries}

Let $(X, d)$ be a metric space, with $X$ nonempty, and let $C B(X)$ be the set of all nonempty closed bounded subsets of $X$. For $A, B \in C B(X)$, let the Pompeiu-Hausdorff metric (a more appropriate name because of historical reasons than the simpler name 'Hausdorff metric' - see the discussion in [33]) $H$ on $C B(X)$ be given by

$$
H(A, B)=\max \left(\sup _{a \in A} d(a, B), \sup _{b \in B} d(b, A)\right)
$$

for any $A, B \in C B(X)$, where $d(x, A)=\inf _{y \in A} d(x, y)$. A fuzzy set $A$ in $X$ is a function from $X$ to $[0,1]$ whose grade of membership of $x$ in $A$ is the function-value $A(x)$. The $\alpha$-level set of $A$ is denoted by $[A]_{\alpha}$ defined by

$$
\begin{aligned}
& {[A]_{\alpha}=\{x \in X: A(x) \geq \alpha\} \subseteq X \quad \text { if } \alpha \in(0,1],} \\
& {[A]_{0}=\overline{\{x \in X: A(x)>0\} \subseteq X,}}
\end{aligned}
$$

where $\bar{B}$ denotes the closure of $B$. Let $F(X)$ be the collection of all fuzzy sets in a metric space $(X, d)$. For $A, B \in F(X), A \subset B$ means $A(x) \leq B(x), \forall x \in X$. Note also that if $\alpha \in[\beta, 1]$ and $\beta \in(0,1]$, then $[A]_{\alpha} \subseteq[A]_{\beta}$. If there exists $\alpha \in[0,1]$ such that $[A]_{\alpha},[B]_{\alpha} \in C B(X)$, then define

$$
\begin{aligned}
& p_{\alpha}(A, B)=\inf _{x \in[A]_{\alpha}, y \in[B]_{\alpha}} d(x, y), \quad D_{\alpha \beta}(A, B)=H\left([A]_{\alpha},[B]_{\beta}\right), \\
& D_{\alpha}(A, B)=D_{\alpha \alpha}(A, B)=H\left([A]_{\alpha},[B]_{\alpha}\right)
\end{aligned}
$$

for $\alpha, \beta \in[0,1]$. Note that $D_{\alpha \beta}(A, B) \neq D_{\beta \alpha}(A, B)$, in general, if $A \neq B$, while $D_{\alpha \beta}(A, B)=$ $D_{\beta \alpha}(B, A)$, and $\max \left(D_{\alpha \beta}(A, B), D_{\beta \alpha}(A, B)\right) \geq D_{\alpha}(A, B)$ if $\alpha \in[\beta, 1]$ and $\beta \in[0,1]$. If $[A]_{\alpha}$, 
$[B]_{\alpha} \in C B(X), \forall \alpha \in[0,1]$, then

$$
\begin{aligned}
& p(A, B)=\sup _{\alpha \in[0,1]} p_{\alpha}(A, B), \quad \bar{d}_{\infty}(A, B)=\sup _{\alpha, \beta \in[0,1]} D_{\alpha \beta}(A, B), \\
& d_{\infty}(A, B)=\sup _{\alpha \in[0,1]} D_{\alpha}(A, B),
\end{aligned}
$$

So that

$$
\bar{d}_{\infty}(A, B)=\sup _{\alpha, \beta \in[0,1]} H\left([A]_{\alpha},[B]_{\beta}\right) \geq d_{\infty}(A, B)=\sup _{\alpha \in[0,1]} H\left([A]_{\alpha},[B]_{\alpha}\right)
$$

The notation $p(x, A)$ means $p(\{x\}, A)$ and a fuzzy set $A$ in a metric linear space $V$ is said to be an approximate quantity if $[A]_{\alpha}$ is compact and convex in $V$ for each $\alpha \in[0,1]$ and $\sup _{x \in V} A(x)=1$.

The collection of all the approximate quantities in a metric linear space $X$ is denoted by $W(X) . T: X \rightarrow F(Y)$ is a fuzzy mapping from an arbitrary set $X$ to $F(Y)$, which is a fuzzy subset in $X \times Y$, and the grade of membership of $y$ in $T(x)$ is $T(x)(y)$.

The notation $f: X \mid Y \rightarrow Z$ means that the domain of the function $f$ from $X$ to $Z$ is restricted to the subset $Y$ of $X$.

The next definition characterizes $p$-cyclic fuzzy mapping in an appropriate way to establish some results of this paper.

Definition 1 Let $p(\geq 2) \in \mathbf{Z}_{+}$and let $X_{i}$ be nonempty subsets of a nonempty abstract set $X, \forall i \in \bar{p}$, and let $d$ be a metric on $X$. A mapping $T: \bigcup_{i \in \bar{p}} X_{i} \rightarrow F\left(\bigcup_{i \in \bar{p}} X_{i}\right)$ is said to be a $p$-cyclic fuzzy mapping from $\bigcup_{i \in \bar{p}} X_{i}$ to $F\left(\bigcup_{i \in \bar{p}} X_{i}\right)$ if

(a) $T: \bigcup_{i \in \bar{p}} X_{i} \mid X_{j} \rightarrow F\left(X_{j+1}\right) ; \forall j \in \bar{p}$.

(b) There is $\alpha(x) \in(0,1]$ such that the $\alpha(x)$-level set $[T x]_{\alpha(x)} \in C B\left(X_{i+1}\right) ; \forall x \in X_{i}, \forall i \in \bar{p}$.

The above definition is understood under the cyclic constraint $X_{p+1}=X_{1}$, and in general with $X_{n p+i}=X_{i}$ for any $i \in \bar{p}$ and any $n \in \mathbf{Z}_{0+}$, so that $X_{j} \equiv X_{i}$ if $j=i(\bmod p)$.

Now, given the sets $X_{i}, \forall i \in \bar{p}$, the $\alpha$-level sets in $F\left(X_{i}\right)$ are $[A]_{\alpha}=\left\{x \in X_{i}: A(x) \geq \alpha\right\}$, where $A(x)$ is the grade of membership of $x \in X_{i}$ in $A \in F\left(X_{i}\right)$ for any $i \in \bar{p}$. Note that for any given $i \in \bar{p}, z_{i} \in X_{i}$ and $\alpha\left(z_{i}\right) \in(0,1],\left[T z_{i}\right]_{\alpha\left(z_{i}\right)}=\left\{x \in X_{i+1}: T z_{i}(x) \geq \alpha\left(z_{i}\right)\right\} \subseteq X_{i+1}$ is the $\alpha\left(z_{i}\right)$-level set of $T z_{i}$ which consists of points in $X_{i+1}$ of guaranteed membership grade not being less than $\alpha\left(z_{i}\right)$. If $T: \bigcup_{i \in \bar{p}} X_{i} \rightarrow F\left(\bigcup_{i \in \bar{p}} X_{i}\right)$ is a $p$-cyclic fuzzy mapping, since $\left[T z_{i}\right]_{\alpha\left(z_{i}\right)}$ is nonempty, there exists $z_{i+1} \in\left[T z_{i}\right]_{\alpha\left(z_{i}\right)} \subseteq X_{i+1}$ such that $\left[T z_{i+1}\right]_{\alpha\left(z_{i+1}\right)}=\left\{x \in X_{i+2}\right.$ : $\left.T z_{i+1}(x) \geq \alpha\left(z_{i+1}\right)\right\} \subseteq X_{i+2}$ is also a nonempty set for some $\alpha\left(z_{i+1}\right) \in(0,1]$ which is contained in the set $\left[T^{2} z_{i}\right]_{\alpha\left(z_{i}\right)} \equiv\left[T\left(T z_{i}\right)\right]_{\alpha\left(z_{i}\right)}$ for some $\alpha\left(z_{i+1}\right) \in(0,1]$. Then, by recursion, there is a sequence $\left\{z_{i+j}\right\} \subseteq \bigcup_{i \in \bar{p}} X_{i}$ satisfying

$$
z_{i+p} \in\left[T z_{i+p-1}\right]_{\alpha\left(z_{i+p-1}\right)} \subseteq \cdots \subseteq\left[T^{p-1} z_{i+1}\right]_{\alpha\left(z_{i+1}\right)} \subseteq\left[T^{p} z_{i}\right]_{\alpha\left(z_{i}\right)} \subseteq X_{i}
$$

for some set of real values $\alpha\left(z_{j}\right) \in(0,1] ; j=i, i+1, \ldots, i+p-1 ; \forall i \in \bar{p}$. The subsequent definition characterizes $\alpha$-fuzzy best proximity points of some subset $X_{i}$ of $p$-cyclic fuzzy mappings. 
Definition 2 Let $T: \bigcup_{i \in \bar{p}} X_{i} \rightarrow F\left(\bigcup_{i \in \bar{p}} X_{i}\right)$ be a $p(\geq 2) \in \mathbf{Z}_{+}$-cyclic fuzzy mapping. For any given $i \in \bar{p}$, a point $z_{i} \in \bar{X}_{i}$ is said to be an $\alpha\left(z_{i}\right)$-fuzzy best proximity point of $X_{i}$ through $T$ for some $\alpha\left(z_{i}\right) \in(0,1]$ if $d\left(z_{i},\left[T z_{i}\right]_{\alpha}\right)=D_{i \alpha\left(z_{i}\right)}=\inf _{x \in X_{i}} d\left(x,[T x]_{\alpha}\right)$.

Remark 3 Note that $D_{i}=d\left(X_{i}, X_{i+1}\right) \leq D_{i \alpha(x)}$ for any $x \in X_{i}, \forall i \in \bar{p}$. Note also that if there is $z_{i} \in X_{i}$ such that $d\left(z_{i},\left[T z_{i}\right]_{\alpha\left(z_{i}\right)}\right)=D_{i}=d\left(X_{i}, X_{i+1}\right)$ for some $i \in \bar{p}$ then there is $z_{i+1} \in\left[T z_{i}\right]_{\alpha\left(z_{i}\right)} \subseteq X_{i+1}$ such that $d\left(z_{i}, z_{i+1}\right)=D_{i}$, since then $D_{i}=D_{i \alpha\left(z_{i}\right)}$. Thus, $z_{i+1} \in \bar{X}_{i+1}$ (then $z_{i+1} \in X_{i+1}$ if $X_{i+1}$ is closed) is a best proximity point of $X_{i+1}$ to $X_{i}$. Also, $z_{i} \in \bar{X}_{i}$ is a best proximity point of $X_{i}$ to $X_{i+1}$ and an $\alpha\left(z_{i}\right)$-best which is also an $\alpha\left(z_{i}\right)$-fuzzy best proximity point of $X_{i}$ through $T$.

The next result relies on the fact that $\alpha$-fuzzy best proximity points through cyclic selfmappings of adjacent subsets of the cyclic disposal which are not best proximity points can have a mutual distance exceeding the $\alpha$-fuzzy best proximity distance $D_{i \alpha}$.

The subsequent result is concerned with the existence of a set of coincident best proximity points and $\alpha$-fuzzy best proximity points each one at each of the subsets of the cyclic disposal of the fuzzy cyclic mapping.

Proposition 4 The following properties hold:

(i) If $T: \bigcup_{i \in \bar{p}} X_{i} \rightarrow F\left(\bigcup_{i \in \bar{p}} X_{i}\right)$ is a $p(\geq 2)$-cyclic fuzzy mapping such that $X_{i}$ and $X_{i+1}$ are closed with the constraints

$$
\sup _{\alpha \in(0,1]}\left(d\left(x,\left[T z_{i}\right]_{\alpha}\right): x \in \bar{X}_{i+2}\right)<D_{i}=d\left(X_{i}, X_{i+1}\right) \leq D_{i+1}=d\left(X_{i+1}, X_{i+2}\right)
$$

for some given $i \in \bar{p}$ and $z_{i} \in X_{i}$ is an $\alpha\left(z_{i}\right)$-fuzzy best proximity point of $X_{i}$ through $T$ for some $\alpha\left(z_{i}\right) \in(0,1]$, which is also a best proximity point of $X_{i}$ to $X_{i+1}$ for the given $i \in \bar{p}$. Then

$$
d\left(z_{i}, z_{i+1}\right)=d\left(z_{i},\left[T z_{i}\right]_{\alpha\left(z_{i}\right)}\right)=d\left(\left[T^{2} z_{i}\right]_{\alpha\left(z_{i}\right)},\left[T z_{i}\right]_{\alpha\left(z_{i}\right)}\right)=D_{i}
$$

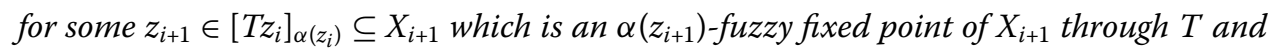
a best proximity point of $X_{i+1}$ to $X_{i+2}$.

(ii) Assume that $T: \bigcup_{i \in \bar{p}} X_{i} \rightarrow F\left(\bigcup_{i \in \bar{p}} X_{i}\right)$ is a $p(\geq 2)$-cyclic fuzzy mapping with $X_{i}$ being closed, $D_{i}=D, \forall i \in \bar{p}$ and there is some $z_{i} \in X_{i}$ which is an $\alpha\left(z_{i}\right)$-fuzzy best proximity point of $X_{i}$ through $T$ for some $\alpha\left(z_{i}\right) \in(0,1]$, which is also a best proximity point of $X_{i}$ to $X_{i+1}$ for some given $i \in \bar{p}$. Then there exists a sequence of points:

$$
z_{i+j+n p} \in\left[T z_{i+j+n p-1}\right]_{\alpha\left(z_{i+j+n p-1}\right)} \subseteq\left[T^{2} z_{i+j+n p-2}\right]_{\alpha\left(z_{i+j+n p-2}\right)} \subseteq \cdots \subseteq\left[T^{j+n p} z_{i}\right]_{\alpha\left(z_{i}\right)} \subseteq X_{i+j}
$$

$\forall j \in \bar{p}, \forall n \in \mathbf{Z}_{0+}$, which satisfy the distance constraints:

$$
\begin{aligned}
d\left(z_{i+j+n p-1}, z_{i+j+n p}\right) & =d\left(z_{i+j+n p-1},\left[T z_{i+j+n p-1}\right]_{\alpha\left(z_{i+j+n p-1}\right)}\right) \\
& =d\left(\left[T^{j+n p+k+1} z_{i}\right]_{\alpha\left(z_{i+k+1}\right)},\left[T^{j+n p+k} z_{i}\right]_{\alpha\left(z_{i+k}\right)}\right)=D ; \quad \forall j \in \bar{p}, \forall n, k \in \mathbf{Z}_{0+}
\end{aligned}
$$

which are best proximity points of $X_{i+j}$ to $X_{i+j+1}$ and $\alpha\left(z_{i+j+n p}\right)$-fuzzy best proximity points through $T$ for some real values $\alpha\left(z_{i+j+n p}\right) \in(0,1], \forall j \in \bar{p}, \forall n, k \in \mathbf{Z}_{0+}$. 
Proof It follows that $d\left(z_{i},\left[T z_{i}\right]_{\alpha}\right)=D_{i}=D_{i \alpha\left(z_{i}\right)}$ since $z_{i} \in X_{i}$ is an $\alpha\left(z_{i}\right)$-fuzzy best proximity point of $X_{i}$ through $T$ which is also a best proximity point of $X_{i}$ to $X_{i+1}$ since $\left[T z_{i}\right]_{\alpha\left(z_{i}\right)} \subseteq X_{i+1}$ is closed.

Note that, for $\alpha\left(z_{i+1}\right) \geq \alpha\left(z_{i}\right)$, one gets

$$
\begin{aligned}
{\left[T z_{i+1}\right]_{\alpha\left(z_{i+1}\right)} } & =\left\{z \in X_{i+2}: T z_{i+1}(z) \geq \alpha\left(z_{i+1}\right)\right\} \\
& \subseteq\left[T^{2} z_{i}\right]_{\alpha\left(z_{i}\right)}=\left\{z \in X_{i+2}: T^{2} z_{i}(z) \geq \alpha\left(z_{i}\right)\right\} .
\end{aligned}
$$

Note also that $d\left(\left[T^{2} z_{i}\right]_{\alpha\left(z_{i}\right)},\left[T z_{i}\right]_{\alpha\left(z_{i}\right)}\right) \geq d\left(X_{i+1}, X_{i+2}\right) \geq D_{i+1}$ and then proceed by contradiction by assuming that the above inequality is strict. Therefore, and since $\left[T z_{i}\right]_{\alpha\left(z_{i}\right)}$ is closed, there is $z_{i+1} \in\left[T z_{i}\right]_{\alpha\left(z_{i}\right)} \subseteq X_{i+1}$ such that $\left[T z_{i+1}\right]_{\alpha\left(z_{i+1}\right)} \subseteq\left[T^{2} z_{i}\right]_{\alpha\left(z_{i}\right)} \subseteq X_{i+2}$ for some $\alpha\left(z_{i+1}\right) \in(0,1]$ so that the following contradiction to the hypothesis $D_{i} \leq D_{i+1}$ for the given $i \in \bar{p}$ is obtained since $D_{i}>\sup _{\alpha \in(0,1]}\left(d\left(x,\left[T z_{i}\right]_{\alpha}\right): x \in \bar{X}_{i+2}\right)$ :

$$
\begin{aligned}
D_{i \alpha\left(z_{i}\right)} & =D_{i}=d\left(z_{i}, z_{i+1}\right)=d\left(z_{i},\left[T z_{i}\right]_{\alpha\left(z_{i}\right)}\right) \\
& >d\left(\left[T z_{i}\right]_{\alpha\left(z_{i}\right)},\left[T z_{i+1}\right]_{\alpha\left(z_{i+1}\right)}\right) \geq d\left(\left[T z_{i}\right]_{\alpha\left(z_{i}\right)},\left[T^{2} z_{i}\right]_{\alpha\left(z_{i}\right)}\right) \geq D_{i+1},
\end{aligned}
$$

and then $D_{i}>D_{i+1}$, which is impossible. Thus, $d\left(\left[T^{2} z_{i}\right]_{\alpha\left(z_{i}\right)},\left[T z_{i}\right]_{\alpha\left(z_{i}\right)}\right)=D_{i+1} \geq D_{i}=$ $d\left(z_{i}, z_{i+1}\right)$. Since $\left[T z_{i+1}\right]_{\alpha\left(z_{i+1}\right)},\left[T^{2} z_{i}\right]_{\alpha\left(z_{i}\right)},\left[T z_{i}\right]_{\alpha\left(z_{i}\right)}$ and $X_{i+1}$ are closed, if $D_{i}=D_{i+1}, z_{i+1} \in$ $\left[T z_{i}\right]_{\alpha\left(z_{i}\right)} \subseteq X_{i+1}$ is a best proximity point of $X_{i+1}$ to $X_{i+2}$ and an $\alpha\left(z_{i+1}\right)$-fuzzy best proximity point of $X_{i+1}$ through $T$ since

$$
d\left(z_{i+1},\left[T z_{i+1}\right]_{\alpha\left(z_{i+1}\right)}\right)=d\left(\left[T^{2} z_{i}\right]_{\alpha\left(z_{i}\right)},\left[T z_{i}\right]_{\alpha\left(z_{i}\right)}\right)=d\left(z_{i+1}, z_{i+2}\right)=D_{i+1}
$$

for some $z_{i+2} \in\left[T z_{i+1}\right]_{\alpha\left(z_{i+1}\right)} \subseteq\left[T^{2} z_{i}\right]_{\alpha\left(z_{i}\right)} \subseteq X_{i+2}$, since $\left[T z_{i+1}\right]_{\alpha\left(z_{i+1}\right)}$ is closed. Property (ii) follows by using the recursion $z_{i+j+n p} \in\left[T z_{i+j+n p-1}\right]_{\alpha\left(z_{i+j+n p-1}\right)} \subseteq \cdots \subseteq\left[T^{j+n p} z_{i}\right]_{\alpha\left(z_{i}\right)} \subseteq X_{i+j}$, $\forall j \in \bar{p}, \forall n \in \mathbf{Z}_{0_{+}}$, and $D_{i}=D, \forall i \in \bar{p}$.

Note that if for some $i \in \bar{p}, z_{i} \in \bar{X}_{i}$ is a best proximity point of $X_{i}$ to $X_{i+1}$ and $\left(\bigcup_{\alpha \in(0,1]}\left[T z_{i}\right]_{\alpha}\right) \neq \emptyset$, then there exists $z_{i+1} \in\left[T z_{i}\right]_{\alpha\left(z_{i}\right)} \subset X_{i+1}$ which is an $\alpha=\alpha\left(z_{i}\right) \in(0,1]$ fuzzy fixed point of $X_{i+1}$ through $T$ which is also a best proximity point of $X_{i+1}$ to $X_{i}$ if $D_{i}=D_{i \alpha\left(z_{i}\right)}=d\left(X_{i}, X_{i+1}\right)$ so that

$$
D_{i}=d\left(z_{i},\left[T z_{i}\right]_{\alpha\left(z_{i}\right)}\right)=d\left(z_{i}, z_{i+1}\right)
$$

If $\left(\bigcup_{\alpha \in(0,1]}\left[T z_{i}\right]_{\alpha}\right)=\emptyset$ and $\left[T z_{i}\right]_{0}(\neq \emptyset) \subset c l X_{i+1}$ and $D_{i}=D_{i 0}$, then $D_{i}=d\left(z_{i},\left[T z_{i}\right]_{0}\right)=$ $d\left(z_{i}, z_{i+1}\right)$ for some $z_{i+1} \in\left[T z_{i}\right]_{0} \subset \bar{X}_{i+1}$ which is a 0 -fuzzy fixed point of $X_{i+1}$ through $T$ and also a best proximity point of $X_{i+1}$ to $X_{i}$.

Definition 5 Let $p(\geq 2) \in \mathbf{Z}_{+}$and let $X_{i}$ be nonempty subsets of a nonempty abstract set $X$, $\forall i \in \bar{p}$, and let $d$ be a metric on $X$. A composite mapping $T(=g f): \bigcup_{i \in \bar{p}} X_{i} \rightarrow F\left(\bigcup_{i \in \bar{p}} X_{i}\right)$ is said to be a decomposable $p$-cyclic fuzzy mapping from $\bigcup_{i \in \bar{p}} X_{i}$ to $F\left(\bigcup_{i \in \bar{p}} X_{i}\right)$ if:

(a) $f: \bigcup_{i \in \bar{p}} X_{i} \mid X_{j} \rightarrow X_{j+1} ; \forall j \in \bar{p}$,

(b) $g: \bigcup_{i \in \bar{p}} X_{i} \mid X_{j} \rightarrow F\left(X_{j}\right) ; \forall j \in \bar{p}$,

(c) there is $\alpha(x) \in(0,1]$ such that the $\alpha(x)$-level set $[T x]_{\alpha(x)} \in C B\left(X_{i+1}\right) ; \forall x \in X_{i}, \forall i \in \bar{p}$. 
The above definition is an extended definition of Definition 1. Note also that $f\left(X_{i}\right) \subseteq X_{i+1}$, $\forall i \in \bar{p}$, and that, since $T=g \circ f$ with $f: \bigcup_{i \in \bar{p}} X_{i} \mid X_{j} \rightarrow X_{j+1}, \forall j \in \bar{p}$ and $g: \bigcup_{i \in \bar{p}} X_{i} \mid X_{j+1} \rightarrow$ $F\left(X_{j+1}\right), \forall j \in \bar{p}$, the cyclic maps $T: \bigcup_{i \in \bar{p}} X_{i} \rightarrow F\left(\bigcup_{i \in \bar{p}} X_{i}\right)$ are restricted to subsets of the cyclic disposal which are of the form $T: \bigcup_{i \in \bar{p}} X_{i} \mid X_{j} \rightarrow F\left(X_{j+1}\right), \forall j \in \bar{p}$. On the other hand, notice that the formalism of contractive cyclic self-maps in uniformly convex Banach spaces requires for the distances in-between any pairs of non-adjacent subsets to be identical. Thus, a fixed point, if any, is a confluent point of pairs of best proximity points inbetween all the intersecting adjacent subsets of the cyclic disposal. On the other hand, note that the case $f: \bigcup_{i \in \bar{p}} X_{i} \mid X_{j} \rightarrow X_{j+1}$ and $g: \bigcup_{i \in \bar{p}} X_{i} \mid X_{j+1} \rightarrow F\left(X_{j+1}\right), \forall j \in \bar{p}$, is a particular case of the more general above problem statement for the cyclic disposal. Now, given the sets $X_{i}, \forall i \in \bar{p}$, we can define the $\alpha$-level sets in $F\left(X_{i}\right)$ by $[A]_{\alpha}=\left\{x \in X_{i}: A(x) \geq \alpha\right\}$, and $A(x)$ is the grade of membership of $x \in X_{i}$ in $A \in F\left(X_{i}\right)$ for any $i \in \bar{p}$.

The following assumption establishes that if $T(=g f): \bigcup_{i \in \bar{p}} X_{i} \rightarrow F\left(\bigcup_{i \in \bar{p}} X_{i}\right)$ is a decomposable $p$-cyclic fuzzy mapping, then the 1-level set of $T x$ intersects with $f x$ for any $x \in \bigcup_{i \in p} X_{i}$. Equivalently, there is at least a point $y \in f x$ such that the grade of membership of $y$ in $T x$ is unity, i.e. $(T x) y=1$, for any $x \in \bigcup_{i \in p} X_{i}$. Note that $f x \subseteq X_{i+1}$ and $[T x]_{1} \subseteq X_{i+1}$, $\forall x \in X_{i}, \forall i \in \bar{p}$.

Assumption 6 If $T(=g f): \bigcup_{i \in \bar{p}} X_{i} \rightarrow F\left(\bigcup_{i \in \bar{p}} X_{i}\right)$ is a decomposable $p$-cyclic fuzzy mapping, then $f x \subseteq[T x]_{1}, \forall x \in \bigcup_{i \in p} X_{i}$.

In other words, Assumption 6 says that any image of $x \in X_{i}$ in $X_{i+1}$ through $f$ belongs to the 1-level set $[T x]_{1} \neq \emptyset$. Note that Assumption 6 implies trivially that $[T x]_{1} \neq \emptyset$, $\forall x \in \bigcup_{i \in p} X_{i}$. Assumption 6 is relevant for identifying best proximity points in-between adjacent subsets through $f$ which are also 1-fuzzy best proximity points through $T$.

Assertion 7 Assume that $T: \bigcup_{i \in \bar{p}} X_{i} \rightarrow F\left(\bigcup_{i \in \bar{p}} X_{i}\right)$ is a decomposable $p$-cyclic fuzzy mapping which satisfies Assumption 6 and that $x \in X_{i}$ for some given arbitrary $i \in \bar{p}$, such that $X_{i}$ is closed. Then, if $x$ is a best proximity point of $X_{i}$ to $X_{i+1}$ through $f$ (in the sense that there exists $y \in f x$ such that $\left.d(x, y)=d\left(X, X_{i}\right)\right)$ then it is an 1-fuzzy best proximity point of $X_{i}$ through $T$.

Proof Since $x \in X_{i}$ is a best proximity point of $X_{i}$ to $X_{i+1}$ through $f$ and $f x \subseteq[T x]_{1}, \forall x \in$ $\bigcup_{i \in p} X_{i}$, then there exists $y \in f x$ such that

$$
D_{i 1}=d\left(x,[T x]_{1}\right) \leq d(x, y)=d(x, f x)=d\left(X, X_{i}\right)=D_{i} \leq D_{i 1} \quad \Rightarrow \quad D_{i}=D_{i 1} .
$$

Then $x$ is an 1-fuzzy best proximity point of $X_{i}$ through $T$.

\section{Some results on $\alpha$-fuzzy best proximity points}

The following result holds related to $\alpha$-fuzzy best proximity points of a $p$-cyclic fuzzy mapping which is contractive in the sense that it is subject to a contractive condition.

Theorem 8 Let $p(\geq 2) \in \mathbf{Z}_{+}$and let $X_{i}$ be nonempty subsets of a non-empty abstract set $X$, $\forall i \in \bar{p}$, where $(X, d)$ is a complete metric space. Let $T: \bigcup_{i \in \bar{p}} X_{i} \rightarrow F\left(\bigcup_{i \in \bar{p}} X_{i}\right)$ be a p-cyclic fuzzy mapping with $X_{i}$ being closed, $\forall i \in \bar{p}$. Assume that the following contractive condition 
holds:

$$
\begin{aligned}
D_{\alpha(x) \alpha(y)}([T x],[T y]) & =H\left([T x]_{\alpha(x)},[T y]_{\alpha(y)}\right) \\
& \leq a_{1} d\left(x,[T x]_{\alpha(x)}\right)+a_{2} d\left(y,[T y]_{\alpha(y)}\right)+a_{3} d(x, y)+(1-a) \Delta ;
\end{aligned}
$$

$\forall x \in X_{i}, \forall y \in X_{i+1}, \forall i \in \bar{p}$, and some $\Delta \in \mathbf{R}_{+}$where $a_{i} \geq 0$ for $i=1,2,3$ and $0<a=$ $\sum_{i=1}^{3} a_{i}<1$.

Then the following properties are fulfilled:

(i) Assume that the following constraints hold:

$$
\begin{aligned}
& 2\left(a_{1}+a_{2}\right)+a_{3}<1, \\
& \Delta=\frac{\left(1-a_{2}-a_{4}\right)\left(1-\rho_{0}\right)}{1-a}, \\
& \rho_{0}=\frac{1}{2}\left[\frac{a_{1}+a_{3}}{1-a_{1}-a_{2}}+\left(\left(\frac{a_{1}+a_{3}}{1-a_{1}-a_{2}}\right)^{2}+4 \frac{a_{2}}{1-a_{1}-a_{2}}\right)^{1 / 2}\right]<1 .
\end{aligned}
$$

Then $\lim \sup _{n \rightarrow \infty} d\left(x_{n}, x_{n+1}\right) \leq \frac{(1-a) \Delta}{\left(1-a_{1}-a_{2}\right)\left(1-\rho_{0}\right)}$, where $x_{n p+j} \in\left[T x_{n p}\right]_{\alpha\left(x_{n p}\right)} \subseteq X_{i+j-1} ; \forall j \in \overline{4}$ for any given initial points $x_{1} \in X_{i}$ and $x_{2} \in X_{i+1}$ for any arbitrary $i \in \bar{p}$.

(ii) For any arbitrarily given $i \in \bar{p}$, a sequence $\left\{x_{n}\right\} \subset \bigcup_{i \in \bar{p}} X_{i}$ can be built for any given $x=x_{1} \in X_{i}, y=x_{2} \in\left[T x_{1}\right]_{\alpha\left(x_{1}\right)} \subseteq X_{i+1}$ fulfilling $x_{n p+j} \in\left[T x_{n p+j-1}\right]_{\alpha\left(x_{n p+j-1}\right)} \subseteq X_{i+j-1} ; \forall j \in \bar{p}, \forall n \in$ $\mathbf{Z}_{0+}$, which fulfills:

$$
\begin{gathered}
d\left(x_{n p+j+2}, x_{n p+j+1}\right) \leq \frac{a_{1}+a_{3}}{1-a_{2}} d\left(x_{n p+j+1}, x_{n p+j}\right)+\frac{1-a}{1-a_{2}} \Delta, \\
\forall j \in \overline{p-1} \cup\{0\}, \forall n \in \mathbf{Z}_{0+},
\end{gathered}
$$

if $\left|N-N_{0}\right| \leq M<\infty$.

(iii) If the constraint (1) holds with $\Delta=D=\min _{i \in \bar{p}} D_{i}$ then the limit below exists:

$$
\lim _{n \rightarrow \infty} d\left(x_{(n+1) p+j+1}, x_{(n+1) p+j}\right)=D, \quad \forall j \in \overline{p-1} \cup\{0\},
$$

so that $D=D_{i}, \forall i \in \bar{p}$, for any sequences constructed as in Property (i). As a result, any sequence $\left\{x_{n}\right\} \subset \bigcup_{i \in \bar{p}} X_{i}$ fulfilling $x_{n p+j} \in\left[T x_{n p+j-1}\right]_{\alpha\left(x_{n p+j-1}\right)} \subseteq X_{i+j-1} ; \forall j \in \bar{p}, \forall n \in \mathbf{Z}_{0+}$, converges to a limit cycle consisting of a set of $p$ best proximity points $x_{i}^{*}$ of the sets $X_{i}, i \in \bar{p}$, which are also $\alpha\left(x_{i-1}^{*}\right)$-fuzzy best proximity points of $X$ through $T=g \circ f: \bigcup_{i \in \bar{p}} X_{i} \rightarrow$ $F\left(\bigcup_{i \in \bar{p}} X_{i}\right)$ for some set of values $\alpha\left(x_{i-1}^{*}\right) \in(0,1]$ and best proximity points of the $p$-cyclic self-mappingf $: \bigcup_{i \in \bar{p}} X_{i} \rightarrow \bigcup_{i \in \bar{p}} X_{i}$.

(iv) If $D=0$ and the constraint holds with $\Delta=D=\min _{i \in \bar{p}} D_{i}$, then any sequence $\left\{x_{n}\right\} \subset \bigcup_{i \in \bar{p}} X_{i}$ fulfilling $x_{n p+j} \in\left[T x_{n p+j-1}\right]_{\alpha\left(x_{n p+j-1}\right)} \subseteq X_{i+j-1} ; \forall j \in \bar{p}, \forall n \in \mathbf{Z}_{0+}$, converges to $x^{*} \in\left[T x^{*}\right]_{\alpha(x *)} \subset \bigcap_{i \in \bar{p}} X_{i}$ which is a unique $\alpha=\alpha\left(x^{*}\right)$-fuzzy fixed point of $T: \bigcup_{i \in \bar{p}} X_{i} \rightarrow$ $F\left(\bigcup_{i \in \bar{p}} X_{i}\right)$. 
Proof Take $x_{1}=x \in X_{i}, x_{2} \in X_{i+1}$, for any given arbitrary $i \in \bar{p}$, there exist $x_{3} \in\left[T x_{1}\right]_{\alpha\left(x_{1}\right)}$, $x_{4} \in\left[T x_{2}\right]_{\alpha\left(x_{2}\right)}$ such that one gets from (1)

$$
\begin{aligned}
d\left(x_{3}, x_{4}\right) \leq & H\left(\left[T x_{1}\right]_{\alpha\left(x_{1}\right)},\left[T x_{2}\right]_{\alpha\left(x_{2}\right)}\right) \\
\leq & a_{1} d\left(x_{1},\left[T x_{1}\right]_{\alpha\left(x_{1}\right)}\right)+a_{2} d\left(x_{2},\left[T x_{2}\right]_{\alpha\left(x_{2}\right)}\right)+a_{3} d\left(x_{1}, x_{2}\right)+(1-a) \Delta \\
\leq & a_{1} d\left(x_{1}, x_{3}\right)+a_{2} d\left(x_{2}, x_{4}\right)+a_{3} d\left(x_{1}, x_{2}\right)+(1-a) \Delta \\
\leq & a_{1} d\left(x_{1}, x_{2}\right)+a_{1} d\left(x_{2}, x_{4}\right)+a_{1} d\left(x_{4}, x_{3}\right) \\
& +a_{2} d\left(x_{2}, x_{3}\right)+a_{2} d\left(x_{3}, x_{4}\right)+a_{3} d\left(x_{1}, x_{2}\right)+(1-a) \Delta \\
= & \left(a_{1}+a_{3}\right) d\left(x_{1}, x_{2}\right)+a_{2} d\left(x_{2}, x_{3}\right)+(1-a) \Delta,
\end{aligned}
$$

so that

$$
d\left(x_{3}, x_{4}\right) \leq \frac{1}{1-a_{1}-a_{2}}\left[\left(a_{1}+a_{3}\right) d\left(x_{1}, x_{2}\right)+a_{2} d\left(x_{2}, x_{3}\right)+(1-a) \Delta\right] .
$$

Then one gets by proceeding recursively for $n \in \mathbf{Z}_{+}$

$$
\begin{aligned}
& d\left(x_{n p+3}, x_{n p+4}\right) \leq \frac{1}{1-a_{1}-a_{2}}\left[\left(a_{1}+a_{3}\right) d\left(x_{n p+1}, x_{n p+2}\right)+a_{2} d\left(x_{n p+2}, x_{n p+3}\right)+(1-a) \Delta\right] \\
& \quad \forall n \in \mathbf{Z}_{0+},
\end{aligned}
$$

where $x_{n p+j} \in\left[T x_{n p}\right]_{\alpha\left(x_{n p}\right)} \subseteq X_{i+j-1} ; \forall j \in \overline{4}$ for the given initial arbitrary $i \in \bar{p}$. Thus,

$$
\left[\begin{array}{l}
d\left(x_{n p+2}, x_{n p+3}\right) \\
d\left(x_{n p+3}, x_{n p+4}\right)
\end{array}\right] \leq\left[\begin{array}{cc}
0 & 1 \\
\frac{a_{2}}{1-a_{1}-a_{2}} & \frac{a_{1}+a_{3}}{1-a_{1}-a_{2}}
\end{array}\right]\left[\begin{array}{l}
d\left(x_{n p+1}, x_{n p+2}\right) \\
d\left(x_{n p+2}, x_{n p+3}\right)
\end{array}\right]+\left[\begin{array}{c}
0 \\
\frac{1-a}{1-a_{1}-a_{2}} \Delta
\end{array}\right] ; \quad \forall n \in \mathbf{Z}_{+} .
$$

The matrix $A_{0}=\left[\begin{array}{cc}0 & \frac{1}{a_{2}} \\ \frac{a_{1}+a_{1}-a_{2}}{1-a_{1}-a_{2}}\end{array}\right]$ is convergent, and then $\left\|A_{0}\right\|^{n} \rightarrow 0$ as $n \rightarrow \infty$ if and only if its eigenvalues $z_{1,2}$ are inside the complex open unit circle, that is, if and only if

$$
z_{1,2}=\frac{1}{2}\left[\frac{a_{1}+a_{3}}{1-a_{1}-a_{2}} \pm\left(\left(\frac{a_{1}+a_{3}}{1-a_{1}-a_{2}}\right)^{2}+4 \frac{a_{2}}{1-a_{1}-a_{2}}\right)^{1 / 2}\right] \in(-1,1)
$$

that is, if and only if $2\left(a_{1}+a_{2}\right)+a_{3}<1$, while the convergence abscissa of $A_{0}$ is

$$
\rho_{0}=z_{2}=\frac{1}{2}\left[\frac{a_{1}+a_{3}}{1-a_{1}-a_{2}}+\left(\left(\frac{a_{1}+a_{3}}{1-a_{1}-a_{2}}\right)^{2}+4 \frac{a_{2}}{1-a_{1}-a_{2}}\right)^{1 / 2}\right]<1 .
$$

Then $\lim _{n \rightarrow \infty} d\left(x_{n p+3}, x_{n p+4}\right)=\frac{(1-a) \Delta}{\left(1-a_{1}-a_{2}\right)\left(1-\rho_{0}\right)}$. Since the initial conditions $x_{1} \in X_{i}$ and $x_{2} \in X_{i+1}$ of the sequence are arbitrary, it follows that $\limsup _{n \rightarrow \infty} d\left(x_{n p+3}, x_{n p+4}\right) \leq$ $\frac{(1-a) \Delta}{\left(1-a_{1}-a_{2}\right)\left(1-\rho_{0}\right)}$. On the other hand, since such conditions are taken for any arbitrary $i \in \bar{p}$, $\limsup _{n \rightarrow \infty} d\left(x_{n}, x_{n+1}\right) \leq \frac{(1-a) \Delta}{\left(1-a_{1}-a_{2}\right)\left(1-\rho_{0}\right)}$. Property (i) has been proved. On the other hand, since for all $x \in X$ there exists $\alpha(x) \in(0,1]$ such that $[T x]_{\alpha(x)} \in C B(X)$ and since any $x \in X$ is in some $X_{i}$ for some $i \in \bar{p}$, we have $[T x]_{\alpha(x)} \in C B\left(X_{i+1}\right)$ for some $i \in \bar{p}$ and some $\alpha(x) \in(0,1]$ for each given $x \in X_{i}$ and any arbitrary $i \in \bar{p}$. As a result, $[T x]_{\alpha(x)}$ and $[T y]_{\alpha(y)}$ are nonempty, closed, and bounded for some existing real values $\alpha(x) \in(0,1]$ and $\alpha(y) \in(0,1] ; \forall x \in X_{i}$, 
$\forall y \in X_{i+1}, \forall i \in \bar{p}$. Since $[T x]_{\alpha(x)} \supseteq[T x]_{\beta(x)}$ if $0<\alpha(x) \leq \beta(x)$ and $[T x]_{\alpha(x),},[T x]_{\beta(x)} \in C B\left(X_{i+1}\right)$, $\alpha(x) \in(0,1]$ can be non-unique with values in $\left(0, \gamma_{i}\right] \subseteq(0,1]$ for some $\gamma_{i} \in \mathbf{R}_{+}$and $x \in X_{i}$ for any arbitrary $i \in \bar{p}$. If the image of the correspondence $c: x \rightarrow \alpha(x)(\in(0,1])$ for some $x \in X$ is such that $[T x]_{\alpha(x)} \in C B(X)$ is non-unique, then it is possible to choose a mapping $m: x \rightarrow \alpha(x)(\subseteq(0,1])$ from Zermelo's axiom of choice to fix $\alpha(x) \in(0,1]$ such that $[T x]_{\alpha(x)} \in C B(X)$. Construct a sequence $\left\{x_{n}\right\} \subset \bigcup_{i \in \bar{p}} X_{i}$ as follows. $x_{1}=x \in X_{i}$ for some arbitrary $i \in \bar{p}$ and some existing $x_{2} \in\left[T x_{1}\right]_{\alpha\left(x_{1}\right)}$ since $\left[T x_{1}\right]_{\alpha\left(x_{1}\right)}$ is nonempty, closed, and bounded for some existing $\alpha\left(x_{1}\right) \in(0,1]$. Since the contractive condition (1) holds for any $x \in X_{i}, \forall y \in X_{i+1}, \forall i \in \bar{p}$, then for $x_{1} \in X_{i}$ it follows that there is $x_{02} \in\left[T x_{1}\right]_{\alpha\left(x_{1}\right)} \subseteq X_{i+1}$ such that $d\left(x_{1}, x_{02}\right)=d\left(x_{1},\left[T x_{1}\right]_{\alpha\left(x_{1}\right)}\right) \leq d\left(x_{1}, x_{2}\right) ; \forall x_{2} \in\left[T x_{1}\right]_{\alpha\left(x_{1}\right)} \subseteq X_{i+1}$, since $\left[T x_{1}\right]_{\alpha\left(x_{1}\right)}$ is closed, thus $x_{02}$ is an $\alpha\left(x_{1}\right)$-fuzzy best proximity points of $X_{i}$ through $T$ and, since $d\left(x_{2},\left[T x_{2}\right]_{\alpha\left(x_{2}\right)}\right) \leq H\left(\left[T x_{1}\right]_{\alpha\left(x_{1}\right)},\left[T x_{2}\right]_{\alpha\left(x_{2}\right)}\right)$ for any $x_{2} \in\left[T x_{1}\right]_{\alpha\left(x_{1}\right)} \subseteq X_{i+1}$, one gets

$$
\begin{aligned}
& d\left(x_{2},\left[T x_{2}\right]_{\alpha\left(x_{2}\right)}\right) \\
& \quad \leq a_{1} d\left(x_{1},\left[T x_{1}\right]_{\alpha\left(x_{1}\right)}\right)+a_{2} d\left(x_{2},\left[T x_{2}\right]_{\alpha\left(x_{2}\right)}\right)+a_{3} d\left(x_{1}, x_{2}\right)+(1-a) \Delta \\
& \quad \leq a_{1} d\left(x_{1}, x_{02}\right)+a_{2} d\left(x_{2},\left[T x_{2}\right]_{\alpha\left(x_{2}\right)}\right)+a_{3} d\left(x_{1}, x_{2}\right)+(1-a) \Delta \\
& \quad \leq a_{1} d\left(x_{1}, x_{2}\right)+a_{2} d\left(x_{2},\left[T x_{2}\right]_{\alpha\left(x_{2}\right)}\right)+a_{3} d\left(x_{1}, x_{2}\right)+(1-a) \Delta \\
& \quad \leq a_{1} d\left(x_{1}, x_{2}\right)+a_{2} d\left(x_{2},\left[T x_{2}\right]_{\alpha\left(x_{2}\right)}\right)+a_{3} d\left(x_{1}, x_{2}\right)+(1-a) \Delta .
\end{aligned}
$$

Then

$$
\left(1-a_{2}\right) d\left(x_{2},\left[T x_{2}\right]_{\alpha\left(x_{2}\right)}\right) \leq\left(a_{1}+a_{3}\right) d\left(x_{1}, x_{2}\right)+(1-a) \Delta
$$

and, since $\left[T x_{2}\right]_{\alpha\left(x_{2}\right)}$ is nonempty and closed, there is some $x_{3} \in\left[T x_{2}\right]_{\alpha\left(x_{2}\right)} \subseteq X_{i+1}$ such that

$$
d\left(x_{2}, x_{3}\right) \leq d\left(x_{2},\left[T x_{2}\right]_{\alpha\left(x_{2}\right)}\right) \leq \frac{a_{1}+a_{3}}{1-a_{2}} d\left(x_{1}, x_{2}\right)+\frac{1-a}{1-a_{2}} \Delta
$$

and since $\left[T x_{2}\right]_{\alpha\left(x_{2}\right)}$ is nonempty and closed, at least one $x_{3}$ may be chosen for which the first inequality of (7) becomes an equality and $x_{2}$ is an $\alpha\left(x_{2}\right)$-fuzzy best proximity points of $X_{i+1}$ through $T$. Proceeding recursively, one sees for the arbitrary given $i \in \bar{p}, \forall j \in \bar{p}$, $\forall n \in \mathbf{Z}_{0+}$, that a sequence in $\bigcup_{i \in \bar{p}} X_{i}$ can be built fulfilling (6) for any arbitrary $i \in \bar{p}$ such that $x_{1}=x \in X_{i}$ is chosen arbitrarily, $x_{2} \in\left[T x_{1}\right]_{\alpha\left(x_{1}\right)} \subseteq X_{i+1}, \ldots, x_{n p+j} \in\left[T x_{n p+j-1}\right]_{\alpha\left(x_{n p+j-1}\right)} \subseteq$ $X_{i+j-1}, x_{n p+j+1} \in\left[T x_{n p+j}\right]_{\alpha\left(x_{n p+j}\right)} \subseteq X_{i+j}, x_{n p+j+2} \in\left[T x_{n p+j+1}\right]_{\alpha\left(x_{n p+j+1}\right)} \subseteq X_{i+j+1}, \ldots ; \forall j \in \bar{p}, \forall n \in$ $\mathbf{Z}_{0+}$, and, furthermore, $x_{n}$ of $\alpha\left(x_{n}\right)$-fuzzy best proximity points of $X$ through $T$ for $n \in \mathbf{Z}_{+}$. Since, from the given hypotheses, $0 \leq K=\frac{a_{1}+a_{3}}{1-a_{2}}<1$ and $0<1-K=\frac{1-a}{1-a_{2}}<1$, so that $(1-$ $K) D=\frac{1-a}{1-a_{2}} \Delta$ if $\Delta=D$, one gets from (7) for $j=p$

$$
\begin{aligned}
d\left(x_{(n+1) p+j+2}, x_{(n+1) p+j+1}\right) \leq & K d\left(x_{(n+1) p+j+1}, x_{(n+1) p+j}\right)+(1-K) \Delta \\
\leq & K^{n p+j} d\left(x_{2}, x_{1}\right)+\left(1-K^{n p+j}\right) \Delta, \\
& \forall n \in \mathbf{Z}_{0+}, \forall j \in \overline{p-1} \cup\{0\} .
\end{aligned}
$$


Thus, one sees from (8) that (3) holds and, furthermore,

$$
\begin{aligned}
& \sum_{n=N_{0}}^{N} d\left(x_{(n+1) p+j+2}, x_{(n+1) p+j+1}\right) \\
& \quad \leq\left(N-N_{0}+1\right) \Delta-K^{\left(j+N_{0}\right) p} \frac{1-K^{\left(N-N_{0}+1\right) p}}{1-K^{p}}\left(\Delta-d\left(x_{2}, x_{1}\right)\right) ;
\end{aligned}
$$

$\forall j \in \overline{p-1} \cup\{0\}$, which leads to (4) if $\left|N-N_{0}\right| \leq M<\infty$. Property (ii) has been proved.

On the other hand, if (1) holds with $\Delta=D=\min _{i \in \bar{p}} D_{i}$, then one gets from (3)

$$
D \leq D_{j+i} \leq \limsup _{n \rightarrow \infty} d\left(x_{(n+1) p+j+1}, x_{(n+1) p+j}\right) \leq D, \quad \forall j \in \overline{p-1} \cup\{0\}
$$

(since $D_{i}<D=\min _{i \in \bar{p}} D_{i}$ is impossible for any $i \in \bar{p}$ ) so that the limit $\lim _{n \rightarrow \infty} d\left(x_{(n+1) p+j+1}\right.$, $\left.x_{(n+1) p+j}\right)=D, \forall j \in \overline{p-1} \cup\{0\}$ exists so that $D=D_{i}, \forall i \in \bar{p}$, and the sequence converges to a limit cycle consisting of a set of $p$ best proximity points $x_{i}^{*}$ of the sets $X_{i}, i \in \bar{p}$, which are also $\alpha\left(x_{i-1}^{*}\right)$-fuzzy best proximity points of $X$ through $T$ for some set of values $\alpha\left(x_{i-1}^{*}\right) \in$ $(0,1]$. Since $d\left(X_{i}, X_{i+1}\right)=D, \forall i \in \bar{p}$, the elements of the limiting set $\left\{x_{i}^{*}: i \in \bar{p}\right\}$ are also best proximity points of the corresponding sets $X_{i}, \forall i \in \bar{p}$. On the other hand, if $D=0$, and since $\lim _{n \rightarrow \infty} d\left(x_{(n+1) p+j+1}, x_{(n+1) p+j}\right)=D, \forall j \in \overline{p-1} \cup\{0\}$, from Property (ii), we have $x_{i}^{*}=x^{*} \in\left[T x^{*}\right]_{\alpha\left(x^{*}\right)}, \forall i \in \bar{p}$, and $\emptyset \neq \bigcap_{i \in \bar{p}}\left[T x^{*}\right]_{\alpha(x *)} \subseteq \bigcap_{i \in \bar{p}} X_{i}$, so that $x^{*}$ is an $\alpha\left(x^{*}\right)$-fuzzy fixed point of $T: \bigcup_{i \in \bar{p}} X_{i} \rightarrow F\left(\bigcup_{i \in \bar{p}} X_{i}\right)$ for some $\alpha \in(0,1]$. We also know the property $[T x]_{\beta} \geq[T x]_{\alpha}$ for all $\beta(\leq \alpha), \alpha\left(\leq \alpha^{*}\right) \in(0,1]$ and some $\alpha^{*} \in(0,1]$. Therefore, there is a real constant:

$$
\alpha^{*}=\alpha^{*}\left(x^{*}\right)=\max \left(\alpha \in(0,1]:\left(\bigcap_{i \in \bar{p}}\left[T x^{*}\right]_{\beta \leq \alpha}\right)\right),
$$

so that $x^{*} \in\left[T x^{*}\right]_{\alpha^{*}}$ is an $\alpha^{*}$-fuzzy fixed point of $T: \bigcup_{i \in \bar{p}} X_{i} \rightarrow F\left(\bigcup_{i \in \bar{p}} X_{i}\right)$ which is the unique limit point of the built sequence.

Now, assume that there are two distinct fuzzy fixed points $x^{*} \in[T x]_{\alpha *}$ and $y^{*} \in[T y]_{\beta *}$. Then one gets from (1) with $\Delta=D=0$, if $x^{*} \in[T x]_{\alpha\left(x^{*}\right)}$ and $y_{1}=y^{*}\left(\neq x^{*}\right) \in \bigcup_{i \in \bar{p}} X_{i}$, and since the level sets are nonempty and closed, and one gets from $(1), d\left(x^{*},[T x]_{\alpha\left(x^{*}\right)}\right)=$ $d\left(y^{*},[T y]_{\alpha\left(y^{*}\right)}\right)=\Delta=D=0$, so that

$$
d\left(x_{2}, y_{2}\right)=d\left(y_{2},\left[T x_{1}\right]_{\alpha^{*}}\right)=D\left(\left[T x_{1}\right]_{\alpha *},\left[T y_{1}\right]_{\alpha\left(y_{1}\right)}\right) \leq a_{3} d\left(x^{*}, y^{*}\right)<d\left(x^{*}, y^{*}\right)
$$

for some $x_{2}=x_{2}\left(y_{2}\right) \in\left[T x_{1}\right]_{\alpha\left(x_{1}\right)}$ and all $y_{2} \in\left[T y_{1}\right]_{\alpha\left(y_{1}\right)}$ with $\alpha\left(x_{1}\right)=\alpha\left(x^{*}\right)=\alpha^{*}$ and $\alpha\left(y_{1}\right)=$ $\alpha\left(y^{*}\right)=\beta^{*}$. Again, one gets from (1) for some $y_{2} \in\left[T y^{*}\right]_{\alpha\left(y^{*}\right)}$, since $y_{1}=y^{*},\left[T y_{1}\right]_{\alpha\left(y_{1}\right)} \equiv$ $\left[T y^{*}\right]_{\alpha(y *)}$ is closed and $x^{*} \in[T x]_{\alpha\left(x^{*}\right)}$,

$$
\begin{aligned}
d\left(x^{*}, y_{2}\right) & =d\left(x^{*},\left[T y_{1}\right]_{\alpha\left(y_{1}\right)}\right) \\
& \leq \max \left(\sup _{y \in\left[T y_{1}\right]_{\alpha\left(y_{1}\right)}} d\left(y,\left[T x^{*}\right]_{\alpha\left(x^{*}\right)}\right), \sup _{x \in\left[T x^{*}\right]_{\alpha\left(x^{*}\right)}} d\left(x,\left[T y_{1}\right]_{\alpha\left(y_{1}\right)}\right)\right) \\
& =H\left(\left[T x^{*}\right]_{\alpha\left(x^{*}\right)},\left[T y^{*}\right]_{\alpha\left(y^{*}\right)}\right) \\
& \leq a_{1} d\left(x^{*},\left[T x^{*}\right]_{\alpha\left(x^{*}\right)}\right)+a_{2} d\left(y^{*},\left[T y^{*}\right]_{\alpha(y *)}\right)+a_{3} d\left(x^{*}, y^{*}\right)
\end{aligned}
$$




$$
\begin{aligned}
& =a_{2} d\left(y_{1},\left[T y_{1}\right]_{\alpha\left(y_{1}\right)}\right)+a_{3} d\left(x^{*}, y_{1}\right) \\
& =a_{3} d\left(x^{*}, y_{1}\right)<d\left(x^{*}, y_{1}^{*}\right)
\end{aligned}
$$

and a sequence $\left\{y_{n}\right\}$ can be built with initial value $y_{1}=y^{*}$ which satisfies

$$
\begin{aligned}
d\left(x^{*}, y_{n+1}\right) & =d\left(x^{*},\left[T y_{n}\right]_{\alpha\left(y_{n}\right)}\right) \\
& \leq \max \left(\sup _{y \in\left[T y_{n}\right]_{\alpha\left(y_{n}\right)}} d\left(y,\left[T x^{*}\right]_{\alpha\left(x^{*}\right)}\right), \sup _{x \in\left[T x^{*}\right]_{\alpha\left(x^{*}\right)}} d\left(x,\left[T y_{n}\right]_{\alpha\left(y_{n}\right)}\right)\right) \\
& \leq a_{2} d\left(y_{n},\left[T y_{n}\right]_{\alpha\left(y_{n}\right)}\right)+a_{3} d\left(x^{*}, y_{n}\right) \\
& \leq a_{2} d\left(y_{n}, y_{n+1}\right)+a_{3} d\left(x^{*}, y_{n}\right), \quad \forall n \in \mathbf{Z}_{+} .
\end{aligned}
$$

Then one gets from (12)

$$
\begin{aligned}
& d\left(x^{*}, y_{n+1}\right) \leq a_{2} d\left(y_{n}, y_{n+1}\right)+a_{3} d\left(x^{*}, y_{n}\right) \leq a_{2}\left(d\left(y_{n}, x^{*}\right)+d\left(x^{*}, y_{n+1}\right)\right)+a_{3} d\left(x^{*}, y_{n}\right) \\
& \leq\left(a_{2}+a_{3}\right) d\left(y_{n}, x^{*}\right)+a_{2} d\left(x^{*}, y_{n+1}\right), \quad \forall n \in \mathbf{Z}_{0+} \\
& \Rightarrow \quad d\left(x^{*}, y_{n+1}\right) \leq\left(1-a_{2}\right)^{-1}\left(a_{2}+a_{3}\right) d\left(y_{n}, x^{*}\right), \quad \forall n \in \mathbf{Z}_{0+}
\end{aligned}
$$

since $a_{2}<1$. If $a_{1} \geq a_{2}$ then $\left(1-a_{2}\right)^{-1}\left(a_{2}+a_{3}\right)<1$, equivalently, $2 a_{2}+a_{3}<1$, since $a=$ $a_{1}+a_{2}+a_{3}<1$ implies that $2 a_{2}+a_{3}<1$ if $a_{1} \geq a_{2}$. On the other hand, one also sees instead of (12) and (14) that a sequence $\left\{x_{n}\right\}$ can be built with initial value $x_{1}=x^{*}$ which satisfies

$$
\begin{aligned}
d\left(y^{*}, x_{n+1}\right) & =d\left(y^{*},\left[T x_{n}\right]_{\alpha\left(x_{n}\right)}\right)=d\left(x^{*},\left[T y_{n}\right]_{\alpha\left(y_{n}\right)}\right) \\
& \leq a_{1} d\left(x_{n}, x_{n+1}\right)+a_{3} d\left(y^{*}, x_{n}\right), \quad \forall n \in \mathbf{Z}_{+}, \\
d\left(x^{*}, x_{n+1}\right) & \leq\left(1-a_{1}\right)^{-1}\left(a_{1}+a_{3}\right) d\left(x_{n}, x^{*}\right), \quad \forall n \in \mathbf{Z}_{+},
\end{aligned}
$$

since $a_{1}<1$. If $a_{1} \leq a_{2}$ then $\left(1-a_{1}\right)^{-1}\left(a_{1}+a_{3}\right)<1$, equivalently, $2 a_{1}+a_{3}<1$, since $a=$ $a_{1}+a_{2}+a_{3}<1$. Since $a<1$, it follows that $\rho=\min \left(\frac{a_{2}+a_{3}}{1-a_{2}}, \frac{a_{1}+a_{3}}{1-a_{1}}\right)<1$. Thus, it follows from (14) that $d\left(x^{*}, y_{n}\right) \rightarrow 0$ as $n \rightarrow \infty$ if $2 a_{2}+a_{3}<1$. Then a sequence with initial condition $y^{*}$ converges to $x^{*}$. Also, one gets from (16) $d\left(y^{*}, x_{n}\right) \rightarrow 0$ as $n \rightarrow \infty$ if $2 a_{1}+a_{3}<1$. Then a sequence with initial condition $x^{*}$ converges to $y^{*}$. Then $x^{*}$ and $y^{*}$ cannot be distinct $\alpha$-fuzzy fixed points. Properties (iii)-(iv) have been proved.

Remark 9 The uniqueness of the limiting fixed point for some $\alpha^{*} \in(0,1]$ of each built sequence proved in Theorem 8 (iv), which is also an $\alpha^{*}$-fuzzy fixed point of $T$, follows from the existence of the maximum $\alpha^{*}$ such that $x^{*} \in\left[T x^{*}\right]_{\alpha^{*}}$. On the other hand, the conclusion of Theorem 8 (iv) that the distances in-between adjacent subsets are identical is not very surprising, since it has been found to be a general property for nonexpansive mappings for $p$-cyclic nonexpansive self-mappings in metric spaces (Lemma 3.3, [5]).

Remark 10 Feasible values of $\Delta$ in the contractive condition (1) might be, for instance,

$$
\begin{aligned}
\Delta & =\bar{d}_{\infty \infty}\left(x_{n}: n \in \mathbf{Z}_{+}\right)=\sup _{j \in \mathbf{Z}_{+}} d_{\infty}\left(\left[T x_{j}\right]_{\alpha\left(x_{j}\right)},\left[T x_{j+1}\right]_{\alpha\left(x_{j+1}\right)}\right) \\
& \leq \sup _{j \in \mathbf{Z}_{+}} d_{\infty}\left(\left[T x_{j}\right]_{\alpha\left(x_{j}\right)},\left[T x_{j+1}\right]_{\alpha\left(x_{j+1}\right)}\right),
\end{aligned}
$$


or $\Delta$ replaced with the $j$ th iteration-dependent values $\Delta_{j}=d_{\infty}\left(\left[T x_{j}\right]_{\alpha\left(x_{j}\right)},\left[T x_{j+1}\right]_{\alpha\left(x_{j+1}\right)}\right)$. From the last expression one also concludes that $\lim _{\sup _{n \rightarrow \infty}} d\left(x_{(n+1) p+j+2}, x_{(n+1) p+j+1}\right) \leq \Delta$, $\forall j \in \overline{p-1} \cup\{0\}$. Both values depend only on the sequences being constructed rather than on the metrics of the sets $X_{i}, i \in \bar{p}$.

Corollary 11 Assume that the contractive condition (1) of Theorem 8 holds with $\Delta=$ $\Delta\left(x,[T x]_{\alpha(x)}\right) \leq D_{\alpha(x) \alpha(y)}\left([T x]_{\alpha(x)},[T y]_{\alpha(y)}\right)$ for all given $x \in X_{i}$ and $y \in[T x]_{\alpha(x)} \subseteq X_{i+1}$ for any given arbitrary $i \in \bar{p}$. Then there is a (non-necessarily unique) sequence $\left\{x_{n}\right\}$ of $\alpha\left(x_{n}\right)$-fuzzy best proximity points of $X$ through $T$ with first element $x \in X_{i}$, being subject to free choice if $\operatorname{card} X_{i} \geq 2$, for any given $i \in \bar{p}$ such that the sequence of distances $\left\{d\left(x_{n}, x_{n+1}\right)\right\}$ is nonincreasing A possible choice is a constant sequence.

Proof The contractive condition (1) now becomes

$$
D_{\alpha(x) \alpha(y)}\left([T x]_{\alpha(x)},[T y]_{\alpha(y)}\right) \leq a^{-1}\left(a_{1} d\left(x,[T x]_{\alpha(x)}\right)+a_{2} d\left(y,[T y]_{\alpha(y)}\right)+a_{3} d(x, y)\right)
$$

$\forall x \in X_{i}, \forall y \in X_{i+1}, \forall i \in \bar{p}$, and, instead of (7), one sees for any $x_{1} \in X_{i}$ for any $i \in \bar{p}$, that there exist (non-unique, in general, see the proof of Theorem 8) $\alpha\left(x_{1}\right) \in(0,1], x_{2} \in\left[T x_{1}\right]_{\alpha\left(x_{1}\right)} \subseteq$ $X_{i+1}, \alpha\left(x_{2}\right) \in(0,1]$, and $x_{3} \in\left[T x_{2}\right]_{\alpha\left(x_{2}\right)} \subseteq X_{i+2}$, since $\left[T x_{1}\right]_{\alpha\left(x_{1}\right)}$ and $\left[T x_{2}\right]_{\alpha\left(x_{2}\right)}$ are nonempty, closed, and bounded:

$$
d\left(x_{2}, x_{3}\right) \leq d\left(x_{2},\left[T x_{2}\right]_{\alpha\left(x_{2}\right)}\right) \leq \frac{a^{-1}\left(a_{1}+a_{3}\right)}{a-a^{-1} a_{2}} d\left(x_{1}, x_{2}\right)=d\left(x_{1}, x_{2}\right)
$$

so that

$$
\begin{aligned}
& d\left(x_{n+2}, x_{n+1}\right) \leq d\left(x_{n+1}, x_{n}\right) \leq \cdots \leq d\left(x_{2}, x_{1}\right), \quad \forall n \in \mathbf{Z}_{0+}, \\
& \limsup _{n \rightarrow \infty} d\left(x_{n+1}, x_{n}\right) \leq d\left(x_{1}, x_{2}\right) \leq d\left(x_{1},\left[T x_{1}\right]_{\alpha\left(x_{1}\right)}\right), \\
& d\left(x_{1}, x_{2}\right)=d\left(x_{1},\left[T x_{1}\right]_{\alpha\left(x_{1}\right)}\right)=D_{i \alpha\left(x_{1}\right)}=\inf _{x_{1} \in X_{i}} d\left(x_{1},\left[T x_{1}\right]_{\alpha\left(x_{1}\right)}\right) \\
& \quad=D_{\alpha\left(x_{1}\right) \alpha\left(x_{2}\right)}\left(\left[T x_{1}\right]_{\alpha\left(x_{1}\right)},\left[T x_{2}\right]_{\alpha\left(x_{2}\right)}\right), \\
& \quad \ldots \\
& \quad d\left(x_{n}, x_{n+1}\right)=d\left(x_{n},\left[T x_{n}\right]_{\alpha\left(x_{n}\right)}\right)=D_{i+n-1, \alpha\left(x_{n}\right)}=\inf _{x_{n} \in X_{n+i-1}} d\left(x_{n},\left[T x_{n}\right]_{\alpha\left(x_{n}\right)}\right) \quad \text { for } n \in \bar{p}, \\
& \quad d\left(x_{(n+1) p+j+2}, x_{(n+1) p+j+1}\right)=d\left(x_{(n+1) p+j+1},\left[T x_{(n+1) p+j+1}\right]_{\alpha\left(x_{(n+1) p+j+1}\right)}\right),
\end{aligned}
$$

with $x_{n p+j+1} \in\left[T x_{n p+j}\right]_{\alpha\left(x_{n p+j}\right)} \subseteq X_{i+j}, \forall j \in \overline{p-1} \cup\{0\}, \forall n \in \mathbf{Z}_{0+}$, for the chosen arbitrary $i \in \bar{p}$ such that $\left\{x_{n}\right\}$ is a sequence of $\alpha\left(x_{n}\right)$-fuzzy best proximity points of $X$ through $T$ with first element $x \in X_{i}$, subject to free choice if $\operatorname{card} X_{i} \geq 2$, for any given $i \in \bar{p}$, and the sequence of distances $\left\{d\left(x_{n}, x_{n+1}\right)\right\}$ is non-increasing.

Corollary 12 A constant sequence exists which satisfies Corollary 11. 
Proof It follows since elements of the sequence $\left\{x_{n}\right\}$ can be chosen so that the first inequalities of (12) and (13) are equalities for $n \in \mathbf{Z}_{+}$so that $d\left(x_{n}, x_{n+1}\right)=d\left(x_{2}, x_{1}\right), \forall n \in \mathbf{Z}_{+}$.

Example 13 Let $X=X_{1} \cup X_{2}$ and $X_{1}=\{1,2,3\},\{1\},\{2\},\{3\}$ and $X_{1}=\{0.6,0.7,0.8\},\{0.6\}$, $\{0.7\},\{0.8\}$ be crisp sets and let $T: X_{1} \cup X_{2} \rightarrow F\left(X_{1} \cup X_{2}\right)$ be a 2-cyclic fuzzy mapping defined as follows:

$$
\begin{aligned}
& T(1)(t)=\left\{\begin{array}{ll}
3 / 4 & \text { if } t=0.8, \\
1 / 2 & \text { if } t=0.7, \\
0 & \text { if } t=0.6 ;
\end{array} \quad T(2)(t)= \begin{cases}0 & \text { if } t=0.8, \\
1 / 3 & \text { if } t=0.7, \\
3 / 4 & \text { if } t=0.6 ;\end{cases} \right. \\
& T(0.8)(t)=\left\{\begin{array}{ll}
3 / 4 & \text { if } t=1, \\
1 / 2 & \text { if } t=2, \\
0 & \text { if } t=3 ;
\end{array} \quad T(0.6)(t)=T(0.7)(t)= \begin{cases}0 & \text { if } t=1, \\
1 / 3 & \text { if } t=2, \\
3 / 4 & \text { if } t=3 .\end{cases} \right.
\end{aligned}
$$

The $\alpha$-level sets are

$$
\begin{aligned}
& {[T 1]_{1 / 2}=[T 3]_{1 / 2}=\{0.7,0.8\},} \\
& {[T 1]_{3 / 4}=[T 3]_{3 / 4}=\{0.8\},} \\
& {[T 0.7]_{\alpha}=[T 0.6]_{\alpha}=\{3\} ; \quad \alpha \in(1 / 2,3 / 4),} \\
& {[T 2]_{\alpha}=\{0.6\} ; \quad \alpha \in(1 / 2,3 / 4),} \\
& {[T 0.8]_{1 / 2}=\{1,2\}} \\
& {[T 0.8]_{3 / 4}=\{1\} .}
\end{aligned}
$$

Let $d: X \times X \rightarrow \mathbf{R}_{0+}$ be the Euclidean norm, then $D=d\left(X_{1}, X_{2}\right)=0.2$. Point to image set distances and Pompeiu- Hausdorff distances are the following:

$$
\begin{aligned}
& d\left(x,[T x]_{\alpha}\right)=0.2 ; \quad x \in\{1,3\}, \alpha \in(1 / 2,3 / 4), \\
& d\left(2,[T 2]_{\alpha}\right)=1.4 ; \quad \alpha \in(1 / 2,3 / 4), \\
& d\left(0.6,[T 0.6]_{\alpha}\right)=d\left(0.7,[T 0.7]_{\alpha}\right)=2.4 ; \quad \alpha \in(1 / 2,3 / 4), \\
& d\left(0.8,[T 0.8]_{\alpha}\right)=0.2 ; \quad \alpha \in(1 / 2,3 / 4),
\end{aligned}
$$

and

$$
\begin{aligned}
& H\left([T 2]_{\alpha},[T y]_{1 / 2}\right)=H\left([T x]_{1 / 2},[T y]_{\alpha}\right)=2.3 ; \quad x=\{1,3\}, y \in\{0.6,0.7\}, \alpha \in\{1 / 2,3 / 4\} \\
& H\left([T 2]_{\alpha},[T y]_{3 / 4}\right)=H\left([T x]_{3 / 4},[T y]_{\alpha}\right)=2.2 ; \quad x=\{1,3\}, y \in\{0.6,0.7\}, \alpha \in\{1 / 2,3 / 4\} \\
& H\left([T 2]_{\alpha},[T 0.8]_{3 / 4}\right)=0.4 ; \quad \alpha \in\{1 / 2,3 / 4\}, \\
& H\left([T 2]_{\alpha},[T 0.8]_{1 / 2}\right)=1.4 ; \quad \alpha \in\{1 / 2,3 / 4\} \\
& H\left([T 0.8]_{3 / 4},[T x]_{1 / 2}\right)=0.3 ; \quad x=\{1,3\} \\
& H\left([T 0.8]_{3 / 4},[T x]_{3 / 4}\right)=0.2 ; \quad x=\{1,3\} \\
& H\left([T 0.8]_{1 / 2},[T x]_{1 / 2}\right)=1.3 ; \quad x=\{1,3\}
\end{aligned}
$$




$$
H\left([T 0.8]_{1 / 2},[T x]_{3 / 4}\right)=1.2 ; \quad x=\{1,3\} .
$$

The contractive constraint (1) and Theorem 8 can be applied with $a_{2}=0.8, a_{1}+a_{3}<1-a_{2}$. Some sequences which converge to $\alpha$-fuzzy best proximity points of $X_{1}$ and $X_{2}$ through $T$, which are also best proximity points in $X_{1}$ of $X_{2}$ and conversely, are

$$
\begin{aligned}
& \left\{1,0.8 \in[T 1]_{3 / 4}, 1 \in[T 0.8]_{3 / 4}, \ldots\right\}, \\
& \left\{1,0.7 \in[T 1]_{1 / 2}, 3 \in[T 0.7]_{3 / 4}, 0.8 \in[T 3]_{3 / 4}, 1 \in[T 0.8]_{1 / 2},\right. \\
& \left.\quad 0.8 \in[T 1]_{3 / 4}, 1 \in[T 0.8]_{3 / 4}, \ldots\right\} .
\end{aligned}
$$

\section{Further results on $\alpha$-fuzzy best proximity points under a more general contractive condition}

We now establish the following result related to a contractive condition which is more general than (1).

Theorem 14 Let $p(\geq 2) \in \mathbf{Z}_{+}$and let $X_{i}$ be nonempty subsets of a nonempty abstract set $X$, $\forall i \in \bar{p}$, where $(X, d)$ is a complete metric space. Let $T: \bigcup_{i \in \bar{p}} X_{i} \rightarrow F\left(\bigcup_{i \in \bar{p}} X_{i}\right)$ be a p-cyclic fuzzy mapping with $X_{i}$ being closed, $\forall i \in \bar{p}$. Assume that the following contractive condition holds:

$$
\begin{aligned}
H\left([T x]_{\alpha(x)},[T y]_{\alpha(y)}\right) \leq & a_{1} d\left(x,[T x]_{\alpha(x)}\right)+a_{2} d\left(y,[T y]_{\alpha(y)}\right)+a_{3} d(x, y) \\
& +a_{4} d\left(x,[T y]_{\alpha(y)}\right)+a_{5} d\left(y,[T x]_{\alpha(x)}\right)+(1-a) \Delta ;
\end{aligned}
$$

$\forall x \in X_{i}, \forall y \in X_{i+1}, \forall i \in \bar{p}$, and some $\Delta \in \mathbf{R}_{+}$where $a_{i} \geq 0$ for $i=1,2,3$ and $0<a=$ $\sum_{i=1}^{5} a_{i}<1$. Then the following properties hold:

(i) For any arbitrarily given $i \in \bar{p}, \forall j \in \bar{p}, \forall n \in \mathbf{Z}_{0+}$, and $x=x_{1} \in X_{i}$, a sequence $\left\{x_{n}\right\} \subset$ $\bigcup_{i \in \bar{p}} X_{i}$ can be built fulfilling $\left\{x_{n}\right\} \subseteq \bigcup_{i \in \bar{p}} X_{i}$ for any given initial points $x_{1}=x \in X_{i}$ for any given $i \in \bar{p}, x_{2} \in\left[T x_{1}\right]_{\alpha\left(x_{1}\right)} \subseteq X_{i+1}, x_{3}=y \in X_{i+1}$, and $x_{4} \in\left[T x_{3}\right]_{\alpha\left(x_{3}\right)} \subseteq X_{i+2}, \forall n \in \mathbf{Z}_{+}$, such that

$$
\limsup _{n \rightarrow \infty}\left\|d\left(x_{n}, x_{n+1}\right)\right\|_{2} \leq \frac{(1-a) \Delta}{\left(1-a_{2}-a_{4}\right)(1-\rho)}
$$

provided that $\theta=a_{2}+a_{4}+2\left(a_{1}+a_{3}\right)+a_{5}<1$, where

$$
\rho=\frac{1}{2}\left(\frac{a_{1}+a_{3}+a_{5}}{1-a_{2}-a_{4}}+\left(\left(\frac{a_{1}+a_{3}+a_{5}}{1-a_{2}-a_{4}}\right)^{2}+4 \frac{a_{1}+a_{3}}{1-a_{2}-a_{4}}\right)^{1 / 2}\right) .
$$

(ii) If $\Delta=D=D_{i} ; \forall i \in \bar{p}, a_{1}=a_{3}=0, \theta=a_{2}+a_{4}+a_{5}<1$, then a sequence $\left\{x_{n}\right\} \subset \bigcup_{i \in \bar{p}} X_{i}$ can be built with initial points $x_{1}=x \in X_{i}$ for any arbitrary given $i \in \bar{p}, x_{2} \in\left[T x_{1}\right]_{\alpha\left(x_{1}\right)} \subseteq X_{i+1}$, $x_{3}=y \in X_{i+1}$, and $x_{4} \in\left[T x_{3}\right]_{\alpha\left(x_{3}\right)} \subseteq X_{i+2}$ which satisfies

$$
\begin{aligned}
& x_{n p+1} \in\left[T x_{n p}\right]_{\alpha\left(x_{n p}\right)} \subseteq X_{i}, \quad x_{n p+2} \in\left[T x_{n p+1}\right]_{\alpha\left(x_{n p+1}\right)} \subseteq X_{i+1}, \\
& x_{n p+3} \in\left[T x_{n p+2}\right]_{\alpha\left(x_{n p+2}\right)} \subseteq X_{i+1}, \quad x_{n p+4} \in\left[T x_{n p+2}\right]_{\alpha\left(x_{n p+2}\right)} \subseteq X_{i+2},
\end{aligned}
$$


and

$$
\begin{aligned}
& d\left(x_{n p+1}, x_{n p+2}\right) \rightarrow D, \quad d\left(x_{n p+2}, x_{n p+3}\right) \rightarrow 0, \quad d\left(x_{n p+3}, x_{n p+4}\right) \rightarrow D, \\
& d\left(x_{n p+4}, x_{n p+5}\right) \rightarrow 0, \quad \ldots
\end{aligned}
$$

as $n \rightarrow \infty$.

Thus, the sequence contains a convergent subsequence to a limit cycle consisting of a set of $p$ best proximity points $x_{i}^{*}$ of the sets $X_{i}$, for $i \in \bar{p}$, which are also $\alpha\left(x_{i-1}^{*}\right)$-fuzzy best proximity points of $X$ through $T$ for some set of values $\alpha\left(x_{i-1}^{*}\right) \in(0,1]$. If $D=0$ then the above convergent subsequence converges to a unique $\alpha=\alpha\left(x^{*}\right)$-fuzzy fixed point of $T: \bigcup_{i \in \bar{p}} X_{i} \rightarrow F\left(\bigcup_{i \in \bar{p}} X_{i}\right)$.

Proof Since $[T x]_{\alpha}$ and $[T y]_{\beta}$ are nonempty and closed for some $\alpha \in\left(0, \gamma_{a}\right] \subseteq(0,1]$ and $\beta \in$ $\left(0, \gamma_{b}\right] \subseteq(0,1]$, we can choose any points $x \in X_{i}$ and $y \in[T x]_{\alpha(x)} \subseteq X_{i+1}$ (then $d\left(y,[T x]_{\alpha(x)}\right)=$ 0 and $\left.d(x, y) \geq d\left(x,[T x]_{\alpha(x)}\right)\right)$. Thus, (22) becomes

$$
\begin{aligned}
d\left(y,[T y]_{\alpha(y)}\right) \leq & H\left([T x]_{\alpha(x)},[T y]_{\alpha(y)}\right) \\
\leq & a_{1} d\left(x,[T x]_{\alpha(x)}\right)+a_{2} d\left(y,[T y]_{\alpha(y)}\right)+a_{3} d(x, y) \\
& +a_{4} d\left(x,[T y]_{\alpha(y)}\right)+(1-a) \Delta \\
\Rightarrow & \\
d\left(y,[T y]_{\alpha(y)}\right) \leq & \left(1-a_{2}\right)^{-1}\left[a_{1} d\left(x,[T x]_{\alpha(x)}\right)+a_{3} d(x, y)+a_{4} d\left(x,[T y]_{\alpha(y)}\right)+(1-a) \Delta\right] \\
\leq & \left(1-a_{2}\right)^{-1}\left[\left(a_{1}+a_{3}\right) d(x, y)+a_{4} d\left(x,[T y]_{\alpha(y)}\right)+(1-a) \Delta\right] .
\end{aligned}
$$

Further assume that $d\left(y,[T y]_{\alpha(y)}\right) \geq d\left(x,[T y]_{\alpha(y)}\right)$ for the chosen $x, y$. Then one gets from (24) the following cases:

Case (a) If $y \in[T x]_{\alpha(x)}$ and $d\left(y,[T y]_{\alpha(y)}\right) \geq d\left(x,[T y]_{\alpha(y)}\right)$ then

$$
d\left(x,[T y]_{\alpha(y)}\right) \leq \frac{1}{1-a_{2}-a_{4}}\left[\left(a_{1}+a_{3}\right) d(x, y)+(1-a) \Delta\right]
$$

Case (b) Assume that $y \in[T x]_{\alpha(x)}$ and $d\left(y,[T y]_{\alpha(y)}\right) \leq d\left(x,[T y]_{\alpha(y)}\right)$ so that, by using those relations in the right-hand side of (23), one gets

$$
\begin{aligned}
d\left(y,[T y]_{\alpha(y)}\right) & \leq H\left([T x]_{\alpha(x)},[T y]_{\alpha(y)}\right) \\
& \leq a_{1} d\left(x,[T x]_{\alpha(x)}\right)+\left(a_{2}+a_{4}\right) d\left(y,[T y]_{\alpha(y)}\right)+a_{3} d(x, y)+(1-a) \Delta ;
\end{aligned}
$$

then

$$
\begin{aligned}
d\left(y,[T y]_{\alpha(y)}\right) & \leq\left(1-a_{2}-a_{4}\right)^{-1}\left[a_{1} d\left(x,[T x]_{\alpha(x)}\right)+a_{3} d(x, y)+(1-a) \Delta\right] \\
& \leq \frac{1}{1-a_{2}-a_{4}}\left[\left(a_{1}+a_{3}\right) d(x, y)+(1-a) \Delta\right] .
\end{aligned}
$$

Joint Cases (a)-(b) The combination of (25) and (27) yields, if $y \in[T x]_{\alpha(x)}$,

$$
\max \left(d\left(x,[T y]_{\alpha(y)}\right), d\left(y,[T y]_{\alpha(y)}\right)\right) \leq \frac{1}{1-a_{2}-a_{4}}\left[\left(a_{1}+a_{3}\right) d(x, y)+(1-a) \Delta\right]
$$


Case (c) If $y \notin[T x]_{\alpha(x)}$ then $d\left(y,[T x]_{\alpha(x)}\right) \neq 0$, so that (28) becomes via (25) and (27) for this case that

$$
\begin{aligned}
& \max \left(d\left(x,[T y]_{\alpha(y)}\right), d\left(y,[T y]_{\alpha(y)}\right)\right) \\
& \quad \leq \frac{1}{1-a_{2}-a_{4}}\left[\left(a_{1}+a_{3}\right) d(x, y)+a_{5} d\left(y,[T x]_{\alpha(x)}\right)+(1-a) \Delta\right],
\end{aligned}
$$

which is more general than (28). Now, construct the sequence $\left\{x_{n}\right\} \subseteq \bigcup_{i \in \bar{p}} X_{i}$ with $x_{1}=x \in$ $X_{i}$ for some given $i \in \bar{p}, x_{2} \in\left[T x_{1}\right]_{\alpha\left(x_{1}\right)} \in X_{i+1}, x_{3}=y \in X_{i+1}$, and $x_{4} \in\left[T x_{3}\right]_{\alpha\left(x_{3}\right)} \in X_{i+2}$ such that $d\left(x_{2}, x_{4}\right)=d\left(x_{2},\left[T x_{3}\right]_{\alpha\left(x_{3}\right)}\right)$, which exists since $\left[T x_{2}\right]_{\alpha\left(x_{2}\right)}$ is nonempty and closed. Thus, one gets after using the triangle inequality $d\left(x_{1}, x_{3}\right) \leq d\left(x_{1}, x_{2}\right)+d\left(x_{2}, x_{3}\right)$ in the right-hand side of (29)

$$
\begin{aligned}
d\left(x_{3}, x_{4}\right) & \leq \max \left(d\left(x_{1}, x_{4}\right), d\left(x_{3}, x_{4}\right)\right) \\
& \leq \frac{1}{1-a_{2}-a_{4}}\left[\left(a_{1}+a_{3}\right) d\left(x_{1}, x_{3}\right)+a_{5} d\left(x_{2}, x_{3}\right)+(1-a) \Delta\right] \\
& \leq \frac{1}{1-a_{2}-a_{4}}\left[\left(a_{1}+a_{3}\right) d\left(x_{1}, x_{2}\right)+\left(a_{1}+a_{3}+a_{5}\right) d\left(x_{2}, x_{3}\right)+(1-a) \Delta\right] .
\end{aligned}
$$

One gets from (30)

$$
\left[\begin{array}{l}
d\left(x_{2}, x_{3}\right) \\
d\left(x_{3}, x_{4}\right)
\end{array}\right] \leq\left[\begin{array}{cc}
0 & 1 \\
\frac{a_{1}+a_{3}}{1-a_{2}-a_{4}} & \frac{a_{1}+a_{3}+a_{5}}{1-a_{2}-a_{4}}
\end{array}\right]\left[\begin{array}{l}
d\left(x_{1}, x_{2}\right) \\
d\left(x_{2}, x_{3}\right)
\end{array}\right]+\left[\begin{array}{c}
0 \\
\frac{1-a}{1-a_{2}-a_{4}} \Delta
\end{array}\right] .
$$

Proceed recursively with (31) by defining the sequence $\left\{x_{n}\right\} \subseteq \bigcup_{i \in \bar{p}} X_{i}$ with initial values $x_{j}$, subject to (30) for $j=1,2,3,4$ and the given arbitrary $i \in \bar{p}$, and a two-dimensional real vector by

$$
v_{n}=\left[\begin{array}{l}
d\left(x_{n+1}, x_{n+2}\right) \\
d\left(x_{n+2}, x_{n+3}\right)
\end{array}\right], \quad \forall n \in \mathbf{Z}_{+},
$$

with initial value $v_{1}=\left[\begin{array}{l}d\left(x_{1}, x_{2}\right) \\ d\left(x_{2}, x_{3}\right)\end{array}\right]$, and a square real 2-matrix $A$ and a two-dimensional vector $d$ defined by

$$
A=\left[\begin{array}{cc}
0 & 1 \\
\frac{a_{1}+a_{3}}{1-a_{2}-a_{4}} & \frac{a_{1}+a_{3}+a_{5}}{1-a_{2}-a_{4}}
\end{array}\right], \quad d=\left[\begin{array}{c}
0 \\
\frac{1-a}{1-a_{2}-a_{4}} \Delta
\end{array}\right] .
$$

Then it is possible to write, in a similar way to (31),

$$
v_{n+1} \leq A v_{n}+d, \quad \forall n \in \mathbf{Z}_{+},
$$

such that for any $x_{n+2} \in X_{j}$, there is $x_{n+3} \in\left[T x_{n+2}\right]_{\alpha\left(x_{n+2}\right)} \subseteq X_{j+1}$ with $j=j(n, i) \in \bar{p}$ depending on the given arbitrary initial $i \in \bar{p}$ with $x_{1} \in X_{i}$ and $x_{2} \in X_{i+1}$. Thus, one gets from (34)

$$
\left\|v_{n p+1}\right\|_{2} \leq\|A\|_{2}\left\|v_{n p}\right\|_{2}+\|d\|_{2}, \quad \forall n \in \mathbf{Z}_{+},
$$


where $\|d\|_{2}$ is the $\ell_{2}$-vector norm of $d$ and

$$
\|A\|_{2}=\sup _{\|\mu\| \leq 1}\left(\frac{\|A \mu\|_{2}}{\|\mu\|_{2}}: \mu \in \mathbf{R}^{2}\right)=\sup _{\|\mu\|=1}\left(\|A \mu\|_{2}: \mu \in \mathbf{R}^{2}\right)=\lambda_{\max }^{1 / 2}\left(A^{T} A\right)
$$

is the $\ell_{2}$ (or spectral)-matrix norm of $A$ (which is the induced $\ell_{2}$-vector norm), where $\lambda_{\max }\left(A^{T} A\right)$ denotes the maximum/real eigenvalue of the (symmetric) matrix $A^{T} A$ and the superscript $T$ denotes matrix transposition. If $\lambda=\|A\|_{2} \in(-1,1)$, then $A$ is a convergent matrix and then $\|A\|_{2}^{n} \rightarrow 0$ as $n \rightarrow \infty$ so that

$$
\begin{aligned}
\left\|v_{n+1}\right\|_{2} & \leq\|A\|_{2}\left\|v_{n}\right\|_{2}+\|d\|_{2} \leq\|A\|_{2}^{n}\left\|v_{1}\right\|_{2}+\|d\|_{2}\left(\sum_{i=0}^{n-1}\|A\|_{2}^{n-i-1}\right) \\
& \leq\|A\|_{2}^{n}\left\|v_{1}\right\|_{2}+\|d\|_{2}\left(\sum_{i=0}^{\infty}\|A\|_{2}^{n-i-1}-\sum_{i=n}^{\infty}\|A\|_{2}^{n-i-1}\right) \\
& \leq \lambda^{n}\left\|v_{1}\right\|_{2}+\frac{1-\lambda^{n}}{1-\lambda}\|d\|_{2} \leq\left\|v_{1}\right\|_{2}+\frac{\|d\|_{2}}{1-\lambda} \\
& =\left\|v_{1}\right\|_{2}+\frac{1-a}{\left(1-a_{2}-a_{4}\right)(1-\lambda)} \Delta<\infty, \quad \forall n \in \mathbf{Z}_{+} .
\end{aligned}
$$

Now, note that if $\rho \in(-1,1)$ is the dominant eigenvalue of $A$, then $\lambda \leq|\rho|<1$ and then, from (36),

$$
\limsup _{n \rightarrow \infty}\left\|d\left(x_{n+3}, x_{n+4}\right)\right\|_{2} \leq \limsup _{n \rightarrow \infty}\left\|v_{n+1}\right\|_{2} \leq \frac{(1-a) \Delta}{\left(1-a_{2}-a_{4}\right)(1-|\rho|)} .
$$

From the definition of the matrix $A$, its eigenvalues are the roots of its characteristic polynomial $p(z)=z^{2}-\frac{a_{1}+a_{3}+a_{5}}{1-a_{2}-a_{4}} z-\frac{a_{1}+a_{3}}{1-a_{2}-a_{4}}$ resulting in

$$
z_{1,2}=\frac{1}{2}\left(\frac{a_{1}+a_{3}+a_{5}}{1-a_{2}-a_{4}} \pm\left(\left(\frac{a_{1}+a_{3}+a_{5}}{1-a_{2}-a_{4}}\right)^{2}+4 \frac{a_{1}+a_{3}}{1-a_{2}-a_{4}}\right)^{1 / 2}\right)
$$

and $\left|z_{1,2}\right|<1$, and then $A$ is a convergent matrix so that (37) holds, if $a_{2}+a_{4}+2\left(a_{1}+a_{3}\right)+$ $a_{5}<1$. Property (i) has been proved.

Now, assume that the sets $X_{i}$ fulfill the constraint $D=D_{i}=d\left(X_{i}, X_{i+1}\right), \forall i \in \bar{p}$, and that the contractive condition holds with $\Delta=\frac{\left(1-a_{2}-a_{4}\right)(1-|\rho|)}{1-a} D \geq D$, or equivalently, with

$$
\rho=|\rho|=z_{2}=\frac{1}{2}\left(\frac{a_{1}+a_{3}+a_{5}}{1-a_{2}-a_{4}}+\left(\left(\frac{a_{1}+a_{3}+a_{5}}{1-a_{2}-a_{4}}\right)^{2}+4 \frac{a_{1}+a_{3}}{1-a_{2}-a_{4}}\right)^{1 / 2}\right)<1 .
$$

But note from (38) that $|\rho| \geq \frac{a_{1}+a_{3}+a_{5}}{1-a_{2}-a_{4}}$ with the equality occurring if and only if $a_{1}=a_{3}=0$. Then, if $\Delta \geq D=D_{i}, \forall i \in \bar{p}, a_{1}=a_{3}=0$, and $\left|z_{1,2}\right| \leq z_{2}<1$, then $\lim _{n \rightarrow \infty}\left\|v_{n p+1}\right\|_{2}=D$. This implies that $d\left(x_{n p+3}, x_{n p+2}\right) \rightarrow 0$ and $d\left(x_{n p+1}, x_{n p+2}\right) \rightarrow D$ as $n \rightarrow \infty$ from (32), since for the definition of the real sequences $\left\{v_{n}\right\}$ and $\left\{x_{n}\right\}, x_{n p+2}$ and $x_{n p+3}$ are both in some set $X_{i+1}$, while $x_{n p+1}$ and $x_{n p+2}$, and $x_{n p+3}$ and $x_{n p+4}$ are, respectively, in the sets $X_{i}$ and $X_{i+2}$, adjacent to $X_{i}$, for any given initial points $x_{1} \in X_{i}$ and $x_{2} \in X_{i+1}$ for any arbitrary $i \in \bar{p}$. This leads directly to the proof of Property (ii). See also the proof of Theorem 8(iii)-(iv) concerning the convergence of the sequence to a set of $\alpha$-fuzzy best proximity points and a unique $\alpha$-fixed point if $D=0$. 
Example 15 Example 13 can also easily be monitored via Theorem 14 via the modified contractive constraint (22) with $a_{4}=a_{5}=0$.

The subsequent definition extends Definition 1 in the sense that an extended $p$-cyclic fuzzy mapping of domain restricted $X_{j}$ has its image in $X_{j} \cup X_{j+1}$ for any $j \in \bar{p}$.

Definition 16 Let $p(\geq 2) \in \mathbf{Z}_{+}$and let $X_{i}$ be nonempty subsets of a nonempty abstract set $X, \forall i \in \bar{p}$, where $(X, d)$ is a metric space. A mapping $T: \bigcup_{i \in \bar{p}} X_{i} \rightarrow F\left(\bigcup_{i \in \bar{p}} X_{i}\right)$ is said to be an extended $p$-cyclic fuzzy mapping from $\bigcup_{i \in \bar{p}} X_{i}$ to $F\left(\bigcup_{i \in \bar{p}} X_{i}\right)$ if:

(a) $T: \bigcup_{i \in \bar{p}} X_{i} \mid X_{j} \rightarrow F\left(X_{j} \cup X_{j+1}\right) ; \forall j \in \bar{p}$,

(b) there is $\alpha(x) \in(0,1]$ such that the $\alpha(x)$-level set $[T x]_{\alpha(x)} \in C B\left(X_{i} \cup X_{i+1}\right) ; \forall x \in X_{i}$, $\forall i \in \bar{p}$.

Theorem 17 Let $p(\geq 2) \in \mathbf{Z}_{+}$and let $X_{i}$ be nonempty subsets of a nonempty abstract set $X$ with $\operatorname{diam}\left(X_{i}\right) \geq D$ and $d\left(X_{i}, X_{i+1}\right)=D ; \forall i \in \bar{p}$, where $(X, d)$ is a complete metric space. Let $T: \bigcup_{i \in \bar{p}} X_{i} \rightarrow F\left(\bigcup_{i \in \bar{p}} X_{i}\right)$ be an extended p-cyclic fuzzy mapping with $X_{i}$ being closed, $\forall i \in \bar{p}$. Assume that the following point-dependent contractive constraint extended from (1) holds:

$$
\begin{aligned}
& H\left([T x]_{\alpha(x),}[T y]_{\alpha(y)}\right) \\
& \quad \leq a_{1_{\left(x,[T x]_{\alpha(x)}\right)}} d\left(x,[T x]_{\alpha(x)}\right)+a_{2_{\left(y,[T y]_{\alpha(y)}\right)}} d\left(y,[T y]_{\alpha(y)}\right) \\
& \quad+a_{3_{(x, y)}} d(x, y)+(1-a) \mu(x, y) D ;
\end{aligned}
$$

$\forall x \in X_{i}, \forall y \in X_{i+1}, \forall i \in \bar{p}$, and some $\Delta \in \mathbf{R}_{+}$where $a_{i_{(\cdot)}} \geq 0$ for $i=1,2,3$, and

$$
\mu(x, y)= \begin{cases}0 & \text { if }(x, y) \in X_{i} \times X_{i+1}, \\ 1 & \text { if } x, y \in X_{i}\end{cases}
$$

for any given $i \in \bar{p}$. Then the following properties hold:

(i) For any arbitrarily given $i \in \bar{p}$, a sequence $\left\{x_{n}\right\} \subset \bigcup_{i \in \bar{p}} X_{i}$ can be built for any given $x=x_{1} \in X_{i}, y=x_{2} \in\left[T x_{1}\right]_{\alpha\left(x_{1}\right)} \subseteq X_{i+1}$ such that $x_{n p+j} \in\left[T x_{n p+j-1}\right]_{\alpha\left(x_{n p+j-1}\right)} \subseteq X_{i+j-1} ; \forall j \in \bar{p}$, $\forall n \in \mathbf{Z}_{0+}$, which fulfills

$$
\lim _{n \rightarrow \infty} d\left(x_{(n+1) p+j+2}, x_{(n+1) p+j+1}\right)=D ; \quad \forall j \in \mathbf{Z}_{0+}
$$

for any $q \in \mathbf{Z}_{0+}$ if $\lim _{n \rightarrow \infty}\left(\prod_{j=0}^{n} \prod_{m=i}^{p+i} \prod_{\ell=1}^{k_{j m}}\left[K_{\text {jm } \ell}\right]\right)=0$, where

$$
K_{j m \ell}=\frac{a_{1 j m \ell}+a_{3 j m \ell}}{1-a_{2 j m \ell}} ; \quad \ell \in k_{j m}, j \in \mathbf{Z}_{0+}, m \in \bar{p},
$$

where the integer subscripts

$$
\ell \in \bar{k}_{j m}, \quad k_{j m}(\leq \bar{k}<\infty) \in \mathbf{Z}_{0+}, \quad j(\leq n) \in \mathbf{Z}_{0+}, \quad m \in \bar{p},
$$

are, respectively, the indicator of each current iteration within the set $X_{m}$, the number of consecutive iterations at the jth tour over the cyclic disposal in the $X_{m}$ set before jumping to 
the $X_{m+1}$ set, the tour counter of completed tours over the cyclic disposal, and the indicator of the current $X_{m}$ set for the iteration.

(ii) If Property (i) holds, then Theorem 8(iii)-(iv) hold.

Proof Define

$$
K\left(x, y,[T x]_{\alpha(x)},[T y]_{\alpha(y)}\right)=\frac{a_{1}\left(x,[T x]_{\alpha(x)}\right)+a_{3}(x, y)}{1-a_{2}\left(y,[T y]_{\alpha(y)}\right)} .
$$

Note that the contractive constraint (39)-(40) leads, in a similar way to (8) in Theorem 8 , to the following inequality:

$$
\begin{aligned}
& d\left(x_{(n+1) p+q+2}, x_{(n+1) p+q+1}\right) \\
& \leq\left(\prod_{j=0}^{n} \prod_{m=i}^{p+i} \prod_{\ell=1}^{k_{j m}}\left[K_{j m \ell}\right] \prod_{m=i}^{\delta+i-1} \prod_{\ell=1}^{k_{j m}}\left[K_{n+1, m \ell}\right] \prod_{\ell=1}^{\hat{k}_{n+1, \delta+i}}\left[K_{n+1, \delta+i, \ell}\right]\right)\left(d\left(x_{1}, x_{2}\right)-D\right)+D ; \\
& \quad \forall n \in \mathbf{Z}_{0+}, j \in \bar{p},
\end{aligned}
$$

for some integer $0 \leq \delta \leq p$, where $0 \leq \hat{k}_{n+1, m}=k_{n+1, m}$ for $i \leq m \leq \delta+i-1,0 \leq \hat{k}_{n+1, \delta+i} \leq$ $k_{n+1, \delta+i}, n \in \mathbf{Z}_{0+}$ is the last completed tour of the cyclic disposal, and

$$
\begin{aligned}
& q=q\left(i, n, \delta, k_{0 m}, \ldots, k_{n m}, \hat{k}_{n+1, \delta+i}\right)=\sum_{j=0}^{n} \sum_{m=i}^{p+i} k_{j m}+\sum_{m=i}^{\delta+i-1} k_{n+1, m}+\hat{k}_{n+1, \delta+i}, \\
& K_{j m \ell}=\frac{a_{1 j m \ell}+a_{3 j m \ell}}{1-a_{2 j m \ell}} ; \quad \ell \in k_{j m}, j \in \mathbf{Z}_{0+}, m \in \bar{p} .
\end{aligned}
$$

Note that $k_{j m} \leq \bar{k}<\infty ; \forall m \in \bar{p}, \forall j \in \bar{n} \cup\{0\}$ and $k_{n+1, j+i} \leq \bar{k}<\infty$ for $j \in \overline{\delta-1} \cup\{0\}$ if $n<\infty$. Now, note also that $\hat{k}_{n+1, \delta+i} \leq \bar{k}<\infty$ if $n \rightarrow \infty$, since the number of sequence tours (tour counter) through the cyclic disposal tends to infinity. It turns out that $\lim _{n \rightarrow \infty} d\left(x_{(n+1) p+q+2}, x_{(n+1) p+q+1}\right)=D$ for any $q \in \mathbf{Z}_{0+}$ as $n \rightarrow \infty$ if

$$
\lim _{n \rightarrow \infty}\left(\prod_{j=0}^{n} \prod_{m=i}^{p+i} \prod_{\ell=1}^{k_{j m}}\left[K_{j m \ell}\right]\right)=0 .
$$

Property (i) has been proved. The proof of Property (ii) is straightforward from Property (i) by similar arguments to those used in the proofs of Theorem 8(iii)-(iv).

Note that Theorem 17 does not require all the elements of the contractive sequence (42) to be less than 1 . The following result is proved for the case when the built sequences are permanent on some of the subsets of the cyclic disposal.

Corollary 18 The following properties hold under the assumptions of Theorem 17:

(i) Theorem 17(i) still holds if there is a finite number $n_{0}$ of complete tours in the cyclic disposal and $\lim _{n \rightarrow \infty}\left(\prod_{\ell=1}^{\hat{k}_{n_{0}+1, \delta+i}}\left[K_{n_{0}+1, \delta+i, \ell}\right]\right)=0$ for some integer $0 \leq \delta \leq p$ with the sequence $\left\{x_{n}\right\}$ being permanent at $\left\{X_{i+\delta}\right\}$. Then $\lim _{n \rightarrow \infty} d\left(x_{(n+1) p+j+2}, x_{(n+1) p+j+1}\right)=0 ; \forall j \in \mathbf{Z}_{0+}$.

(ii) The sequence converges to a unique $\alpha=\alpha\left(x^{*}\right)$-fuzzy fixed point $x^{*}$ of $T: \bigcup_{i \in \bar{p}} X_{i} \rightarrow$ $F\left(\bigcup_{i \in \bar{p}} X_{i}\right)$ allocated in $\left[T x^{*}\right]_{\alpha\left(x^{*}\right)} \subseteq X_{i+\delta}$. 
Proof Property (i) follows from (45) for $n \leq n_{0}<\infty$ and $\hat{k}_{n_{0}+1, \delta+i} \rightarrow \infty$. Property (ii) follows from Property (i) since $(X, d)$ is complete and $[T x]_{\alpha(x)}$ is closed for any $x \in \bigcup_{i \in \bar{p}} X_{i}$ in a similar way to the proof of Theorem 8 (iv).

Example 19 Define the linear metric space $(X, d)$ with $X$ being the union of closed real intervals $X_{1}=\left[-r_{1},-D / 2\right], X_{2}=\left[D / 2, r_{2}\right]$ subject to

$$
r_{1}>3 D / 2 \geq 0, \quad \min \left(r_{1}, r_{2}\right)>0, \quad \max \left(r_{1}, r_{2}\right)<+\infty,
$$

and which have mutual and Pompeiu-Hausdorff distances $d\left(X_{1}, X_{2}\right)=D$ and $H\left(X_{1}, X_{2}\right)=$ $D+\max \left(r_{1}, r_{2}\right)$, respectively. Consider some extended 2-cyclic fuzzy mapping $T: X_{1} \cup$ $X_{2} \rightarrow F\left(X_{1} \cup X_{2}\right)$ whose restrictions of domain are to the two subsets $X_{1}$ and $X_{2}$ fulfill $T: X_{1} \cup X_{2}\left|X_{1} \rightarrow F\left(X_{1} \cup X_{2}\right), T: X_{1} \cup X_{2}\right| X_{2} \rightarrow F\left(X_{1}\right)$. Such a map is defined in such a way that it constructs iterative sequences which are ordered with two consecutive elements $x_{n}, x_{n+1} \in\left[T x_{n}\right]_{1} \subset X_{1}$ and the next one $x_{n+2} \in\left[T x_{n+1}\right]_{1} \subset X_{2}$, and which satisfies the constraints:

$$
\begin{aligned}
& d\left(x_{n+1}, x_{n}\right) \leq \rho d\left(x_{n}, x_{n-1}\right) \quad \text { if } x_{n}, x_{n+1} \in\left[T x_{n}\right]_{1} \subset X_{1}, \\
& d\left(x_{n+2}, x_{n+1}\right) \leq K d\left(x_{n}, x_{n-1}\right)+(1-K) D \quad \text { if } x_{n+2} \in\left[T x_{n+1}\right]_{1} \subset X_{2},
\end{aligned}
$$

for $n \in \mathbf{Z}_{+}$subject to $K^{2} \rho<1$. Note that either $K$ or $\rho$ (but not both of them) cannot be less than unity. Since the 1-level sets are nonempty and contain the points, identified with their associated crisp sets, we can consider $F\left(X_{1}\right)$ and $F\left(X_{2}\right)$ as approximate quantities [22, 28], since $X_{1}$ and $X_{2}$ are compact and convex, and such crisp sets, equivalently as points, obtained from a maximum defuzzifier [34], since there exists a compact $[T x]_{1}(\neq$ $\emptyset) \subseteq[T x]_{\alpha(x)}$ for any $x \in X_{1} \cup X_{2}$ and any $\alpha(x) \in(0,1]$. Assume that $x_{1}, x_{2} \in X_{1}$ and $x_{3} \in X_{2}$, and then $x_{2 n} \in\left[T x_{2 n-1}\right]_{1} \subset X_{1}, x_{2 n+1} \in\left[T x_{2 n}\right]_{1} \subset X_{1}, x_{2 n+2} \in\left[T x_{2 n+1}\right]_{1} \subset X_{2} ; \forall n \in \mathbf{Z}_{+}$, and one gets

$$
\begin{aligned}
& d\left(x_{2 n+1}, x_{2 n}\right) \leq\left(K^{2} \rho\right)^{n} d\left(x_{1}, x_{2}\right)+\left(1-K^{n}\right) D, \\
& d\left(x_{2 n+2}, x_{2 n+1}\right) \leq K d\left(x_{2 n+1}, x_{2 n}\right)+(1-K) D, \\
& \lim _{n \rightarrow \infty} d\left(x_{2 n+1}, x_{2 n}\right)=\lim _{n \rightarrow \infty} d\left(x_{2 n+2}, x_{2 n+1}\right)=D .
\end{aligned}
$$

If $x_{1} \in X_{2}$ and $x_{2}, x_{3} \in X_{1}, x_{2 n} \in\left[T x_{2 n-1}\right]_{1} \subset X_{2}, x_{2 n+1} \in\left[T x_{2 n}\right]_{1} \subset X_{1}$, and $x_{2 n+2} \in\left[T x_{2 n+1}\right]_{1} \subset$ $X_{1} ; \forall n \in \mathbf{Z}_{+}$, the same conclusion for the distance limits as above follows. In both cases, sequences converging to the limit cycle $\{-3 D / 2,-D / 2, D / 2\}$ are obtained for any initial conditions $x_{1}, x_{2} \in X_{1}$ or $x_{1} \in X_{2}, x_{2} \in X_{1}$. All the sequences are not necessarily converging to the above limit cycle, in general, unless it be assumed that $T: X_{1} \cup X_{2} \rightarrow F\left(X_{1} \cup X_{2}\right)$ is such that $[T x]_{\alpha(x)}=[T x]_{1} ; \forall x \in X_{1} \cup X_{2}$. 


\section{Author details}

${ }^{1}$ Institute of Research and Development of Processes, University of the Basque Country, Campus of Leioa (Bizkaia), Barrio Sarriena, P.O. Box 644, Bilbao, 48940, Spain. ²Department of Mathematics, University of Jaén, Paraje de las Lagunillas s/n, Jaén, 23071, Spain. ${ }^{3}$ Department of Mathematics, Texas A\&M University - Kingsville, 700 University Blvd., Kingsville, TX 78363-8202, USA. ${ }^{4}$ Department of Mathematics, Faculty of Science, King Abdulaziz University, Jeddah, 21589, Saudi Arabia.

\section{Acknowledgements}

The first author thanks the Spanish Ministry of Economy and Competitiveness for partial support of this work through Grant DPI2012-30651. He also thanks the Basque Government for its support through Grant IT378-10, and to the University of Basque Country by its support through Grant UFI 11/07. Finally, the authors thank the referees for their useful suggestions

\section{Received: 13 April 2015 Accepted: 11 June 2015 Published online: 02 July 2015}

\section{References}

1. De la Sen, M, Ibeas, A: Properties of convergence of a class of iterative processes generated by sequences of self-mappings with applications to switched systems. J. Inequal. Appl. 2014, Article ID 498 (2014)

2. De la Sen, M, Karapınar, E: On a cyclic Jungck modified TS-iterative procedure with application schemes. Appl. Math Comput. 233, 383-397 (2014)

3. De la Sen, M: About robust stability of Caputo linear fractional dynamic systems with time delays through fixed point theory. Fixed Point Theory Appl. 2011, Article ID 867932 (2011)

4. De la Sen, M, Alonso-Quesada, S, Ibeas, A: On the asymptotic hyperstability of switched systems under integral-type feedback regulation Popovian constraints. IMA J. Math. Control Inf. (in press). doi:10.1093/imamci/dnt045

5. Karpagam, S, Agrawal, S: Best proximity point theorems for $p$-cyclic Meir-Keeler contractions. Fixed Point Theory Appl. 2009, Article ID 197308 (2009)

6. De la Sen, M: Linking contractive self-mappings and cyclic Meir-Keeler contractions with Kannan self-mappings. Fixed Point Theory Appl. 2010, Article ID 572057 (2010). doi:10.1155/2010/572057

7. Di Bari, C, Suzuki, T, Vetro, C: Best proximity points for cyclic Meir-Keeler contractions. Nonlinear Anal., Theory Methods Appl. 69(11), 2790-3794 (2008)

8. Rezapour, S, Derafshpour, M, Shahzad, N: On the existence of best proximity points of cyclic contractions. Adv. Dyn. Syst. Appl. 6(1), 33-40 (2011)

9. Al-Thagafi, MA, Shahzad, N: Convergence and existence results for best proximity points. Nonlinear Anal., Theory Methods Appl. 70(10), 3665-3671 (2009)

10. Derafshpour, M, Rezapour, S, Shahzad, N: Best proximity points of cyclic $\phi$-contractions on reflexive Banach spaces. Fixed Point Theory Appl. 2010, Article ID 946178 (2010)

11. Choudhury, BS, Das, K, Bhandari, SK: Cyclic contraction result in 2-Menger space. Bull. Int. Math. Virtual Inst. 2(1), 223-234 (2012)

12. Beg, I, Abbas, M: Fixed point and best approximation in Menger convex metric spaces. Arch. Math. 41, 389-397 (2005)

13. Beg, I, Latif, A, Abbas, M: Coupled fixed points of mixed monotone operators on probabilistic Banach spaces. Arch. Math. 37, 1-8 (2001)

14. De la Sen, M, Karapınar, E: Some results on best proximity points of cyclic contractions in probabilistic metric spaces. J. Funct. Spaces 2015, Article ID 470574 (2015)

15. De la Sen, M, Agarwal, RP, Ibeas, A: Results on proximal and generalized weak proximal contractions including the case of iteration-dependent range sets. Fixed Point Theory Appl. 2014, Article ID 169 (2014)

16. Gabeleh, M: Best proximity point theorems via proximal non self-mapping. J. Optim. Theory Appl. 164(2), 565-576 (2015)

17. Heilpern, S: Fuzzy mappings and fixed point theorem. J. Math. Anal. Appl. 83, 566-569 (1981)

18. Ahmed, MA: Fixed point theorems in fuzzy metric spaces. J. Egypt. Math. Soc. 22, 59-62 (2014)

19. Chitra, A, Subrahmanyam, PV: Fuzzy sets and fixed points. J. Math. Anal. Appl. 124, 584-590 (1987)

20. Grabiec, M: Fixed points in fuzzy metric space. Fuzzy Sets Syst. 27, 385-389 (1998)

21. Singh, B, Jain, S, Jain, S: Generalized theorems on fuzzy metric spaces. Southeast Asian Bull. Math. 31, $963-978$ (2007)

22. Azam, A, Beg, l: Common fuzzy fixed points for fuzzy mappings. Fixed Point Theory Appl. 2013, Article ID 14 (2013)

23. Cho, YJ, Pathak, HK, Kang, SM, Jung, JS: Common fixed points of compatible mappings of type $(\beta)$ on fuzzy metric spaces. Fuzzy Sets Syst. 93, 99-111 (1998)

24. Qiu, D, Shu, L: Supremum metric on the space of fuzzy sets and common fixed point theorems for fuzzy mappings. Inf. Sci. 178, 3595-3604 (2008)

25. Abbas, M, Altun, I, Gopal, D: Common fixed point theorems for non compatible mappings in fuzzy metric spaces. Bull. Math. Anal. Appl. 1(2), 47-56 (2009)

26. Phiangsungnoen, S, Sintunavarat, W, Kumam, P: Common $\alpha$-fuzzy fixed point theorems for fuzzy mappings via $\beta_{F}$-admissible pair. J. Intell. Fuzzy Syst. 27, 2463-2472 (2014)

27. Jain, A, Sharma, A, Gupta, V, Tiwari, A: Common fixed point theorem in fuzzy metric space with special reference to occasionally weakly compatible mappings. J. Math. Comput. Sci. 4(2), 374-383 (2014)

28. Turkoglu, D, Rhoades, BE: A fixed fuzzy point for fuzzy mapping in complete metric spaces. Math. Commun. 10 115-121 (2005)

29. Singh Sisodia, K, Singh, D, Rathore, MS: A common fixed point theorem for subcompatibility and occasionally weak compatibility in intuitionistic fuzzy metric spaces. Gen. Math. Notes 21(1), 73-85 (2014)

30. Manro, S, Bouharjera, H, Singh, S: A common fixed point theorem in intuitionistic fuzzy metric space by using sub-compatible maps. Int. J. Math. Sci. 5, 2699-2707 (2010)

31. Roldan, A, Karapı, nE, Manro, S: Some new fixed point theorems in fuzzy metric spaces. J. Intell. Fuzzy Syst. 27 2257-2264 (2014)

32. Jleli, M, Karapı, nE, Samet, B: On cyclic $(\psi, \phi)$-contractions in Kaleva-Seikkala's type fuzzy metric spaces. J. Intell. Fuzzy Syst. 27, 2045-2053 (2014) 
33. Berinde, $\mathrm{V}$, Pacurar, M: The role of Pompeiu-Hausdorff metric in fixed point theory. Creative Math. Inform. 22(2), 143-150 (2013)

34. Wang, LX: Adaptive Fuzzy Systems and Control: Design and Stability Analysis. Prentice Hall, Englewood Cliffs (1994)

Submit your manuscript to a SpringerOpen ${ }^{\odot}$ journal and benefit from:

- Convenient online submission

Rigorous peer review

- Immediate publication on acceptance

- Open access: articles freely available online

- High visibility within the field

- Retaining the copyright to your article

Submit your next manuscript at $\boldsymbol{s p r i n g e r o p e n . c o m ~}$ 